
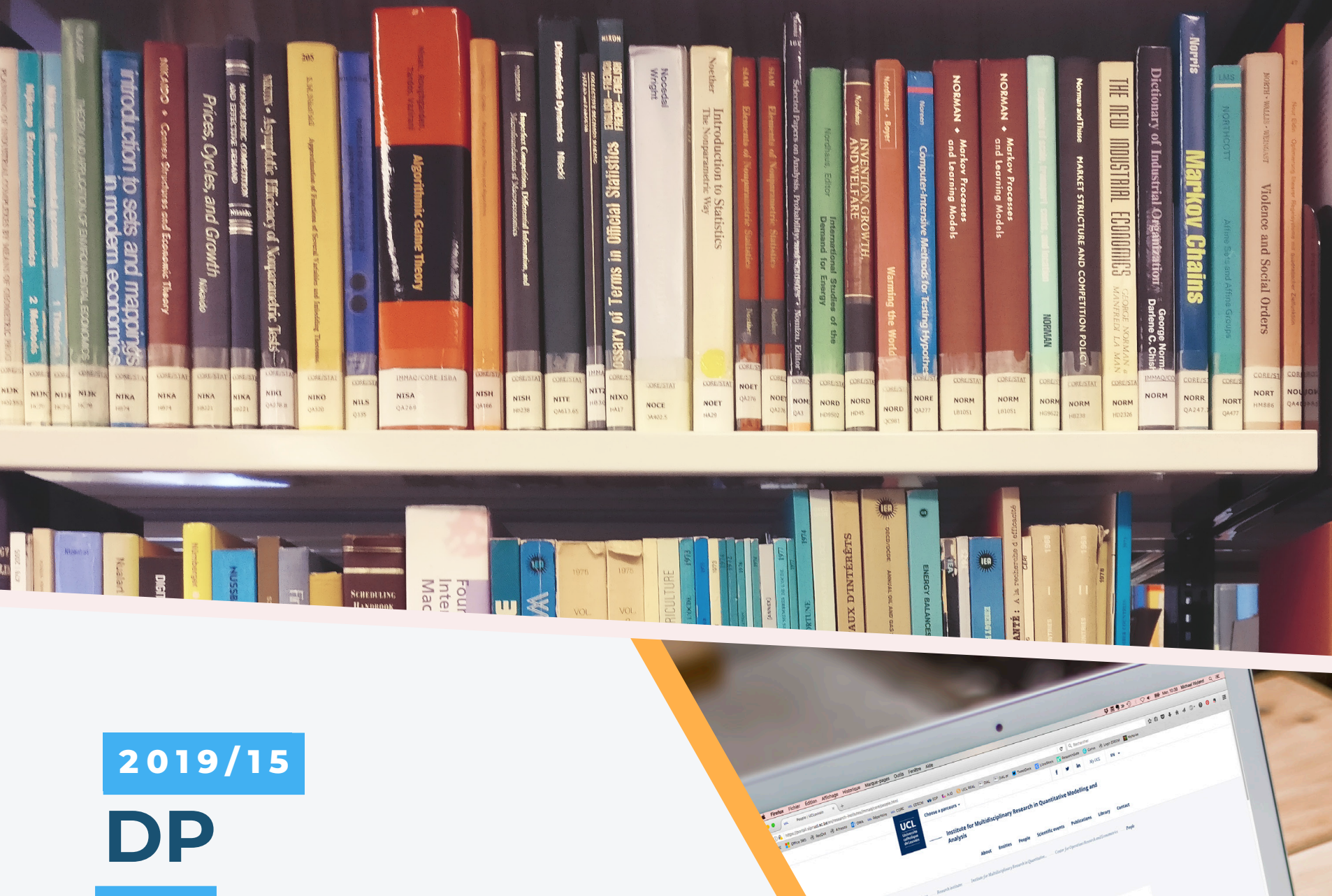

Sophie Béreau, Jean-Yves Gnabo and Henri Vanhomwegen

Making a difference:

European mutual funds

distinctiveness and

peers' performance 


\section{CORE}

Voie du Roman Pays 34, L1.03.01

B-1348 Louvain-la-Neuve

Tel (32 10) 474304

Email: immaq-library@uclouvain.be

https://uclouvain.be/en/research-institutes/

lidam/core/discussion-papers.html 


\title{
Making a difference:
}

\section{European mutual funds distinctiveness and peers' performance}

\author{
Sophie Béreau ${ }^{\mathrm{a}, \mathrm{b}}$, Jean-Yves Gnabo ${ }^{\mathrm{a}, \mathrm{c}}$, Henri Vanhomwegen ${ }^{\mathrm{a}}$ \\ ${ }^{a}$ CeReFiM and naXys, University of Namur \\ ${ }^{\mathrm{b}}$ CORE, UCLouvain \\ c EconomiX-CNRS, University of Paris Nanterre
}

\begin{abstract}
Skilled managers of equity mutual funds can develop innovative strategies to outsmart their style peers. We unveil various causes of distinct invest-ment strategies and test whether they materialize into outperformance of peer competitors. We frame our paper on European funds and propose a novel procedure to measure and test the impact of strategy distinctiveness while dealing with endogenous style classification and sample noise in peers' comparisons of performance. We find a strong, robust and positive impact of strategy distinctiveness on financial performance. Yet, the marginal effect decreases with the level of distinctiveness.
\end{abstract}

J.E.L. classification: G11, G12, G23

Keywords: European equity mutual funds, distinctiveness, commonality, peer performance, adaptive clustering 


\section{Introduction}

Whether or not an investment fund is able to consistently outperform its competitors is still highly debated in the academic literature. In their chase for higher "alpha", funds considering to be endowed with enough skills can decide to make their way "apart from the crowd" - to quote Vozlyublennaia and $\mathrm{Wu}(2017)$ - by developing singular strategies. Meanwhile, others limit themselves to follow the average behaviour of their peers' competitors.

The main issue we explore in this study is whether it is worth differentiating oneself from its peers in the mutual funds industry. We do it by addressing the two following questions: (i) Do distinct strategies materialize into outperformance of peer competitors? And (ii) what are the key drivers of distinct strategies? Both questions are empirically examined with care in the poorly documented context of the European mutual funds industry. In a nutshell, our main findings are the following. First, we demonstrate that European Equity Mutual Funds (EEMF hereafter) generate on average higher risk-adjusted performance than their close competitors when they follow "distinct" strategies. This effect is nonlinear though. Hence, the marginal effect tends to decrease with the level of distinctiveness. Also, consistently with the notion of "migration risk", we show that the transition towards more distinct strategies can be costly as a fast shift is associated with lower returns. Second, looking at the underlying motivations, we unveil that most distinct funds are young and of small size.

These results provide new empirical evidence on funds' performance adding to an already rich literature (see Ferreira, Keswani, Miguel and Ramos, 2013 as general references as well as Sun, Wang and Zheng, 2012 and Vozlyublennaia and Wu, 2017 on style, distinctiveness, and fund performance). Specifically, we contribute to the line of research testing the ability of particularly "skilled" funds that implement innovative strategies to beat their competitors. The rationale behind this test can be summed up as follows. Funds' competition exists primarily within styles (such as, Eurozone LargeCap Equity, or France Large-Cap Equity for instance), with funds developing investment strategies to outperform their style peers (Hoberg, Kumar and Prabhala, 2017). As these styles are only broadly defined, they leave funds enough latitude to differentiate themselves from direct competitors - other funds following the same style - in order to generate higher gains (see notably, Daniel, Grinblatt, Titman and Wermers, 1997; Sun et al., 2012; and 
more recently Hoberg et al., 2017). Whether such an objective is reached in practice in the asset management industry remains however an open question that academic research can contribute to document.

To be addressed, however, this question requires dealing with several empirical caveats. Most notably, we need to identify the set of relevant competitors - that is funds following the same style - to which each fund should be compared to and to determine a methodology to confront the respective performance. The first caveat stems from the lack of reliable information about fund style. As discussed in Sensoy (2009) for instance, self-reported styles are subject to strategic manipulation from investment funds (see also Hoberg et al., 2017) albeit casting doubt on their accuracy. To circumvent this issue, the literature proposes as a main alternative to apply statistical tools to retrieve the set of institutions following the same style from the dependence between funds' characteristics such as total net assets' returns (see Brown and Goetzmann, 1997, Sun et al., 2012). ${ }^{1}$ Another caveat concerns the procedure to follow in order to compare funds' performance, that is to gauge how well a fund performs with respect to its competitors. Because usual "absolute" indicators of risk-adjusted performance such as three- or four-factor alphas are estimated quantities, they are not directly comparable across funds and require specific econometric treatment to account for sampling error Ardia and Boudt (2018). For instance, two funds can display different estimated alphas but such difference could be too small for the true unobserved alphas to be actually deemed as different. As subsequently detailed, each problem is far from trivial and needs to be addressed very carefully to draw sound conclusions. In this paper, we apply recent econometric methods as well as machine learning types of approach to deal with these issues. In particular, we apply an endogenous dynamic clustering approach called the "Adaptive Forgetting Factor for Evolutionary Clustering and Tracking" methodology (hereafter, AFFECT, from Xu, Kliger and Hero iii, 2014) to retrieve the number of style at each period and allocate each fund to its style. From there, we compute the strategy distinctiveness index (SDI hereafter) of Sun et al. (2012). This metric enables to setup a distance between each fund and its style peers. Next, we implement the peer performance test developed by Ardia and Boudt (2018) which is immune from the so-called "false discovery" problem (see Barras, Scaillet and Werm-

\footnotetext{
${ }^{1}$ An alternative approach used in Cremers and Petajisto (2009) among others consists in using similarity in portfolio holdings.
} 
ers, 2010) in order to assess the fraction of competitors beaten by a specific fund. Eventually, we use panel regression analyses to both test the impact of the SDI on peer performance and reveal the determinants of SDI. For the sake of comparison, we also propose alternative approaches to estimate our relationships of interest, including for instance either a specification with the original four-factor alpha (Carhart, 1997) as a dependent variable to measure the mutual fund performance or a specification with variables based on a clustering method applied to rolling windows with fixed length as in Sun et al. (2012).

Another obstacle to confront in order to conduct this research is to access comprehensive data on European mutual funds. As noted above, compared to the US mutual funds industry, the European market has been poorly documented so far despite a substantial growth over the past decades. To do the analysis, we have collected a novel database comprising 4,957 EEMFs totalling 1,014 trillion of capital under management by the end of 2016 .

The closest study to ours is Sun et al. (2012). We build and extend their initial analysis in a number of ways. First, we focus on the mutual fund industry as opposed to the the hedge industry in the reference study. The literature on the hedge funds' and mutual funds' industries have grown handin-hand over several decades with contributions exploring separate as well as common issues. While hedge funds have long been considered far more risky and aggressive than mutual funds, growing risk taking in the mutual funds industry as reported in Choi and Kronlund (2017) make the assessment of their strategy along with their resulting performance increasingly important. Second, we use data on European domiciled funds as opposed to US domiciled funds in Sun et al. (2012). The mutual funds industry has been substantially growing outside the US with Europe being responsible for a large part of this growth. For example, the European equity mutual fund market has expended by more than $400 \%$ ( $\$ 722 \mathrm{bn}$ to $\$ 4.1 \mathrm{tn}$ ) as compared to $200 \%$ over the same period, for the US (ICI, 2017) between 1999Q1 and 2016Q4. In total, the size of the EEMF market reached 3.8 trillion of assets under management (AUM) in 2016- an amount representing 37\% of that of the U.S. equity mutual fund (EMF) industry and $23 \%$ of the global EMF industry (EFAMA, 2017). Importantly, Ferreira et al. (2013) notice in their crosscountry analysis on mutual funds substantial differences in the determinants of fund performance in the US and elsewhere in the world casting doubt whether US-based findings could be extrapolated to other markets. They show for instance that the well-known relationship between the fund size 
and performance differ markedly when comparing US with non-US domicile funds. As noted by Banegas, Gillen, Timmermann and Wermers (2013) improving our understanding of EEMFs, their environment or their strategy is critical for a large set of actors, including investors, regulators or policymakers. To our knowledge, there exists no evidence on the link between strategy distinctiveness and financial performance for European institutions. Third, we propose a modified version of Sun et al. (2012) procedure to compute the strategy distinctiveness index. Such procedure is based on a fully dynamic and endogeneous clustering approach (hereafter referred as adaptive approach) as opposed to simple rolling-window approach (hereafter referred as non-adaptive approach) in its original form. As discussed in Section 3, style identification is a central ingredient in the measure of strategy distinctiveness. Our approach should therefore provide a more accurate measure of strategy distinctiveness. Fourth, we adopt a more consistent approach of funds' performance. Sun et al. (2012) define the competitive environment of each fund as the set of funds following the same style. Their strategy distinctiveness measure is consistently computed with respect to this specific set of competitors. However, subsequently in their analysis, the fund's performance is based on a risk-adjusted alpha, supposing implicitly that each fund is set in competition with the whole universe of funds. In the spirit of Cohen, Coval and Pástor (2005) and other contributions on "peer alpha" (Hunter, Kandel, Kandel and Wermers, 2014), we measure fund's performance as a fund's risk-adjusted returns relative to the risk-adjusted returns of its competitors exclusively (i.e. funds belonging to the same style). Then, we rely on statistical tests when doing the comparison to control for sampling noise. ${ }^{2}$ Fifth, we explore the existence of non-linearity in the relationship between strategy distinctiveness and financial performance, to assess the existence of an optimal distance or a transition cost when shifting towards innovative strategy due to migration risk. ${ }^{3}$

Overall, our work provides new empirical evidences regarding mutual funds and the role of distinct strategy. Our results support the existence of a strong and positive link between strategy distinctiveness and the relative perfor-

\footnotetext{
2 Note that for the sake of comparison, we also provide regressions with the traditional four-factor model Carhart (1997) to measure risk-adjusted performance.

3 Migration risk stems from the lack of knowledge or expertise of funds managers when they start implementing new strategies. It is usually associated to changes of style. However, this principle can arguably be extended to changes occurring within a style as study in our analysis when a fund shifts to more singular and innovative strategies.
} 
mance measured by the percentage of peers outperformed. This finding is robust to a series of sensitivity tests, including the use of traditional fourfactor alpha as a measure of absolute performance. In this case, our findings mean that singular strategies help better perform than both its (style) peer competitors as well as the rest of the market. Turning to the determinants of fund's distinctiveness, fund age, volatility, and total net asset (TNA) values are found to be negative drivers of strategy distinctiveness. These results confirm previous results on other segments of the asset management industry or other markets. In particular, our results are consistent with Sun et al. (2012) and Vozlyublennaia and $\mathrm{Wu}$ (2017) who, with the exception of age for the latter, found the same type of relationship between the aforementioned fund characteristics and strategy distinctiveness for U.S. hedge funds and U.S. mutual funds, respectively. We also unveil new features, such as the impact of cluster-related characteristics on future performance. The results of non-linear specifications provide interesting nuances into the analysis. Specifically, we highlight (i) a stronger effect of strategy distinctiveness on financial outperformance during the crisis period, (ii) a lower performance when the shift towards more innovative strategies is fast and (iii) the existence of a tipping point at which the positive marginal effect of the strategy distinctiveness variable dies out. As a results, although following innovative strategies pays off on average, the effect is actually nonlinear and exhibits a threshold level over which being too different becomes useless.

The remainder of this paper is structured as follows: in Section 2, we discuss our data. In Section 3, we detail our methodology to dynamically assess funds' clusters, which then allows for measurements of funds' distinctiveness among their peers and for quantifying how this characteristic affects performance and other aggregates across time. In Section 4, we provide an overview of the EEMF industry and detail our results from regression analyses. Finally, Section 5 provides the conclusion.

\section{Data}

We create an original database on EEMFs. To that aim, we take advantage of micro-level data - fund-level information - on EMFs domiciled in a broad range of European countries. The EEMF data are extracted from the 
Morningstar Direct database. Morningstar is widely used in the asset management literature (see Sensoy, 2009, Patel and Sarkissian, 2017). Among key advantages of the Morningstar Direct database are its comprehensive coverage across countries and time, and the presence of non-surviving and surviving funds, making it free from survivor bias. Information on fund attributes is available at various frequencies. For the purpose of the present study, we collect daily prices along with returns ${ }^{4}$ and TNA values, both at a monthly frequency. We also retrieve several other fund characteristics, such as fund age and flows (see Table 1 for details).

\section{[Insert Table 1 about here]}

We recover a total of 8,520 EMFs for the 1999-2016 period. Then, we apply successive filters consistent with the literature (Sun et al., 2012, Ferreira et al., 2013). For instance, we exclude fund with less than 10 observations and less than 10M of asset under management. We further exclude fund of funds, index tracking fund and fund not traded in euro. In addition, styles representing less than $1 \%$ of the population of funds and the associated funds have been excluded. We end up with 4,957 funds dispatched into 22 distinct styles as identified by Morningstar (see Table 2).

[Insert Table 2 about here]

The total TNA ( $\sim 1$ trillion) of selected funds by the end of 2016 amounted to almost $40 \%$ of our target industry (EFAMA, 2017, Morningstar, 2016). The list of European countries and their corresponding populations of funds are displayed in Table 3.

[Insert Table 3 about here]

\footnotetext{
${ }^{4}$ Morningstar does not adjust total returns for sales charges or redemption fees. However, the data account for management, administrative, and 12b-1 fees, as well as other costs automatically deducted from fund assets.
} 
Compared to the existing academic literature, the strength of our database is threefold. First, the database covers a large number of funds. For a matter of comparison, the aforementioned studies of Sun et al. (2012) and Vozlyublennaia and $\mathrm{Wu}$ (2017) dealing with the determinants of investments funds' performance in the US market rely on 3896 and 3519 funds respectively. Second, information is available at a relatively high frequency with key attributes observed every month. Third, we embrace nearly two decades of European data and covers both crisis and post-crisis periods. To our knowledge, the most comparable databases are used in Banegas et al. (2013) and Graef, Vogt, Vonhoff and Weigert (2018) who also cover the European segment of the mutual funds industry. We can also add to these studies the research of Ferreira et al. (2013) which provide a worldwide analysis of mutual funds. In their analysis, European domiciled mutual funds account for 4438 funds over 12,577 mutual funds in total and observations span from 1997 to 2007. Graef et al. (2018) included 1,464 European funds from 2001 to 2017 at a semi-annual frequency, whereas Banegas et al. (2013) comprised 4,200 funds from 1988 to 2008 at a monthly frequency. Therefore, we provide additional insights into the European EMFs industry.

\section{Empirical methodology}

The objective of the empirical analysis is to investigate the impact of EEMFs' distinctiveness (relative to peers) on future performance, along with its causes. To this end, we propose a modified version of the approach developed by Sun et al. (2012) which addresses several econometric caveats associated with the data. In Section 3.1, we detail our empirical approach to retrieve endogenous styles and compute fund-level strategy distinctiveness over time. In Section 3.2, we present the regression setting.

\subsection{Strategy distinctiveness index}

To capture the degree of distinctiveness or, inversely, the degree of similarity, among EEMF investments at both system-wide and individual levels, we follow the general setup proposed by Sun et al. (2012), which relies on a 
measure of distance between funds' net asset returns. The underlying motivation for using such a proxy is simply that we expect closer net asset returns for funds exhibiting similar portfolios that are supposed to reflect similar investment strategies. An alternative is to directly rely on the information related to portfolio holdings of funds (Cremers and Petajisto, 2009, Gupta-Mukherjee, 2013) and measure the deviation from a passive benchmark. However, those data are not easily accessible ${ }^{5}$ and net asset returns are available at a higher frequency, providing more flexibility to document the evolution of commonalities over time.

As previously noted, our main measure is constructed by following the set-up developed by Sun et al. (2012) to compute the so-called "strategy distinctiveness index" (SDI). In their contribution, this index aims to assess how distinct and unique a fund strategy is relative to its peers. Formally, the SDI measure (1) is calculated for each fund $i$ as follows:

$$
\begin{aligned}
& S D I_{i, t}=1-\operatorname{corr}\left(r_{i, t}, \mu_{I, t}\right) \\
& =1-\frac{\sum_{t=1}^{24}\left(r_{i, t}-\bar{r}_{i}\right)\left(\mu_{I, t}-\bar{\mu}_{I}\right)}{\sqrt{\sum_{t=1}^{24}\left(r_{i, t}-\bar{r}_{i}\right)^{2} \sum_{t=1}^{24}\left(\mu_{I, t}-\bar{\mu}_{I}\right)^{2}}} \\
& \text { Where } \mu_{I, t}=\frac{\sum_{i \in I} r_{i, t}}{\operatorname{count}(i \in I)}
\end{aligned}
$$

Thus, this metric corresponds to 1 minus the correlation between the fund's returns $\left(r_{\mathrm{i}, \mathrm{t}}\right)$ and the average returns of all funds belonging to the same cluster or style indexed by I $\left(\mu_{I, t}\right)$. The higher the SDI, the more distinct the investment strategy of a fund appears with respect to its peers from the same cluster. To obtain a time-varying measure consistent with the monthly frequency of our analysis, correlations are computed as realised correlation that is in our case within-month correlations from daily returns. ${ }^{6}$

One critical aspect of the methodology lies in the identification of fund styles. A fund's style governs the broad direction of the investment strategy, such as

${ }^{5}$ Working with portfolio holdings generally involves a high cost because the data collection is long and taxing. It also often limits the number of funds to be considered as well as the frequency of data. For instance, Cremers and Petajisto (2009), Gupta-Mukherjee (2013) include no more than 3000 mutual funds at a quarterly frequency.

6 Sun et al. (2012) applied rolling windows of 24 months over the entire sample. Our approach consisting in using within month correlation allows to avoid arbitrary choice for the size of the rolling windows. It is also more consistent with the monthly frequency used in the regression part of the analysis. 
concentrating its investment in a specific region or class of assets. Within a style, funds can make decisions depending on their skills or talent to innovate and depart from their peers. Therefore, pairing funds according to their style is a pivotal step in subsequently gauging the innovativeness of each strategy relative to style-based peers. For fund managers, peer funds following a similar style are particularly relevant for comparison because they constitute their natural "rivals" or "competitors"7, as stated by Hoberg et al. (2017) (see also DiBartolomeo and Witkowski, 1997, Brown and Goetzmann, 1997). To allocate mutual funds into styles across time, we follow two strategies that both infer the style directly from the data: first we rely on a traditional rolling-window approach which we refer as "non-adaptive". Second, we apply an "adaptive" clustering method (Xu et al., 2014). In the next sections, we further elaborate on those approaches.

\subsubsection{Non-adaptive cluster algorithm}

Ample anecdotal evidence exists in the press and more formal evidence exists in the academic literature showing that self-reporting of style by fundsthe so-called prospectus - can provide a misleading picture of the actual style-based strategy of funds. A simple reason is that a financial institution may have strategic interest to misreport its style by announcing ex-post to have followed a style to mask poor performance with respect to its true strategy (see Sensoy, 2009, Cremers and Petajisto, 2009, Hoberg et al., 2017). In response, several contributions have proposed alternative approaches to endogenously retrieving from the data style-based categories and the associated fund allocations. The identification procedure builds on the intuition that funds, being similar or close to each other, should be placed into a common group, whereas those appearing more distant from each other should be placed into different groups. Each group will then stand for the unobserved underlying style. Equipped with distance measures for all pairs of funds, alternative clustering techniques can be applied to allocate them into consistent

${ }^{7}$ Hoberg et al. (2017) considered institution-specific competitors. As is subsequently discussed in this paper, we adopt a more conventional definition of the set of competitors in which all funds belonging to the same style are assumed to be direct competitors. This approach has the advantage of being transitive, namely, if fund $\mathrm{A}$ is a rival to fund $\mathrm{B}$ and fund $\mathrm{B}$ a rival to fund $\mathrm{C}$, then we assume that $\mathrm{A}$ and $\mathrm{C}$ are rivals, which was not guaranteed with the Hoberg et al. (2017) methodology. 
groups. In practice, the allocation of mutual funds into accurate similaritybased categories is not easy. Here, we follow Brown and Goetzmann (1997, 2001) and Sun et al. (2012) to group our sets of funds in a consistent manner by applying clustering algorithms on funds' net asset returns. The seminal approach on which we rely is the well-known "K-means" algorithm (Hartigan, 1975) with a very simple and intuitive rationale. Hence, considering a set of $n$ observations and $K$ clusters specified ex-ante ${ }^{8}$, the "K-means" algorithm aims to find a partition such that the squared error between the empirical mean of each cluster and the points in the cluster is minimized. In other words, the observations are grouped into K clusters such that each one belongs to the group with which the associated mean exhibits the closest distance. The process is traditionally iterative. First, K observations of the dataset are assigned as the initial cluster means. Second, observations are gathered according to their nearest mean, which is computed as the smallest Euclidean distance. ${ }^{9}$ Then, the process iterates between step one and step two until the results converge to a final segmentation of the data. An important critique that should be noted of the previous algorithm concerns its static nature because it has been designed to address non-dynamic systems. There are cases however in which we observe time variations in both the composition and the number of clusters. The asset management industry is part of these cases. By essence, the industry evolves continuously through time given the appearance and disappearance of funds or changes in styles due to changing market conditions and perceived profitability. One way to address the time-varying nature of styles and associated clusters is to implement static methods over rolling windows, as in Brown and Goetzmann (1997, 2001) and Sun et al. (2012). As such, static clustering methods are applied to successive sub-samples of fixed size. As is explained further down, we refer to those methods as "non-adaptive." As discussed in the statistical literature (see Zivot and Wang, 2006, Clark and McCracken, 2009) such approaches suffer from various empirical problems. In particular, the choice of the largely arbitrary bandwidth or window size constitutes a crucial assumption that has been proven to significantly impact results of studies using

\footnotetext{
${ }^{8}$ In our empirical application, we define $K$ as the number of existing styles as identified by Morningstar.

9 Alternative metrics have also been suggested in the literature as potential extensions, such as the Mahalanobis distance (Mao and Jain, 1996), the L1 distance (Kashima, Hu, Ray and Singh, 2008) or the family of Bregman distances (Banerjee, Dhillon, Ghosh, Merugu and Modha, 2007) to quote only a few.
} 
fixed window width. For instance, dividing long time series characterised by a time dependence structure may artificially generate outliers that, in addition to the limited time span of the data within the windows, can severely bias the estimations. Overall, estimations performed over rolling windows can thus provide a misleading picture of the system over time, which calls for alternative approaches that are specifically designed to account for dynamic structures.

\subsubsection{Adaptive cluster algorithm}

In recent years, alternative statistical clustering techniques have been developed in the machine learning literature to address temporal systems; see, for instance, Yang, Harris, Luo, Xiong, Joachimiak, Wu, Dehal, Jacobsen, Yang, Palumbo et al. (2009), Xu et al. (2014) and more recently Matias and Miele (2017). Here, we rely on the AFFECT algorithm that has been specifically designed to address dynamic clusters. The main advantages of AFFECT relative to the previous rolling window methodology is that it allows for controlling the rate at which past proximities are forgotten in an adaptive way. In other words, it allows the data to speak by estimating rather than arbitrarily fixing the optimal level of smoothing at each time step. Another advantage of relaxing the requirement of arbitrary short sequences (24 months in our case) is the ability to directly consider entries and exits in the market, which allows to mitigate the survivorship bias more effectively than in a non-adaptive setting where complete information is required. Moreover, compared to the aforementioned methodology, AFFECT avoids data overlap. Indeed proximities in the adaptive setting are computed in each month, only using the within-month daily returns. The AFFECT algorithm is iterative and proceeds in several structured steps. First, as an initialization phase, the algorithm computes a matrix of proximities in $t=1$ to which is further applied a standard static clustering method (e.g., $\mathrm{K}$-means in our case). In our context, we use as the initial proximity matrix, the dot product matrix of funds' daily net return time series normalized in each month, which corresponds to a correlation matrix between the returns. Then, the similarity matrices at each time step are obtained by revising past information thanks to a state-space representation featuring a parameter the "adaptive forgetting factor" - shown to be a function of past similarity 
matrices. As such, this method assumes that the time-varying observed matrix of proximities $\left(\mathrm{W}_{\mathrm{t}}\right)$ can be modeled as a linear combination of a true (latent) proximity matrix $\left(\Psi_{t}\right)$ plus a zero-mean noise matrix $N_{t}$. Xu et al. (2014) proposed a smoothing estimation procedure of $\Psi_{t}$ as an alternative to the standard Kalman filter procedure. More specifically, it consists of a convex combination of static estimation $W_{t}$ through static clustering techniques and past smoothed proximity matrix $\left(\hat{\Psi}_{t-1}\right)$

$$
\begin{aligned}
& W_{t}=\Psi_{t}+N_{t} \\
& \hat{\Psi}_{t}=\alpha_{t} \hat{\Psi}_{t-1}+\left(1-\alpha_{t}\right) W_{t} \\
& \text { with } \quad \hat{\Psi}_{0}=W_{0}
\end{aligned}
$$

$\alpha_{t}$ controls the rate at which past proximities are forgotten and is thus referred to as the "forgetting factor." The forgetting factor's identification is performed through a shrinkage estimation thanks to a block-model representation (see for more details Xu et al., 2014). Whereas the true value for the $\alpha$ parameter is interpreted by the authors as the "oracle forgetting factor," which requires perfect knowledge of the true proximity matrix $\left(\Psi_{t}\right.$ ) as well as the noise variance $\left(\mathrm{N}_{\mathrm{t}}\right)$. Xu et al. (2014) proposed an estimator on the basis of sample counterparts of theoretical moments on which it depends, which are the sample mean and variance of $\mathrm{W}_{\mathrm{t}}$. However, given that both $\Psi_{\mathrm{t}}$ and $\mathrm{N}_{\mathrm{t}}$ are time varying, the authors suggested using spatial mean and variance. Finally, because estimation requires full unknown information about the block structure (cluster structure), it is performed adaptively (in practice, up to three iterations are required to make the process converge).

\subsubsection{Adaptive vs non-adaptive cluster algorithms}

Table 4 provides preliminary insights regarding the constitution of our clusters when applying the adaptive and non-adaptive approaches. We document the stability of the clusters by computing two measures. Cluster stability depicts the percentage of similarity (in terms of associated funds) at two consecutive periods. The statistic reaches $79 \%$ in the adaptive setting as compared to $75 \%$ for the non-adaptive one. Cluster switch corresponds to the percentage of funds migrating from one cluster to another for at least two consecutive months. Results show that funds switch styles $15.7 \%$ of the 
time in the adaptive approach for $19.01 \%$ in the non-adaptive one. Overall, these figures are very much in lines with the ones of Sun et al. (2012) (16.6\%) for US hedge funds and Brown and Goetzmann (1997) (17.6\%) for US mutual funds and are consistent with the idea that the funds are following one long term global strategy - i.e. their style - but can occasionally migrate to another style. We also report information regarding our largest and smallest styles in terms of population of funds.

[Insert Table 4 about here]

Eventually, for the overlapping year, we cross check our classification with the one proposed by Morningstar (Table 5). A similar exercise is conducted by Sun et al. (2012) which cross-check their hedge funds classification with the one retrieved from Lipper TASS. Overall, we observe some consistency between the classifications. Considering the best match (i.e the highest number of funds in each category which match with a specific style-cluster) $57 \%$ of the funds that are grouped together in Morningstar are still together with our clustering algorithm. If we take the cumulative proportion of the two largest match we reach $76 \%$.

[Insert Table 5 about here]

Equipped with those two alternative procedures (adaptive clustering and non-adaptive clustering), we can compute SDI measures in the cluster of reference for each fund (i.e., the group of peers following the same style) over time. Table 6 features the evolution over time (yearly basis) of the computed SDI index (monthly average over all funds) based on the adaptive K-means generated from the AFFECT algorithm (column I) and alternatively from the non-adaptive K-means (column II). As explained previously the adaptive setting does not rely on rolling-windows and incorporates directly available data on a monthly basis (reducing the loss of data compared to rolling-window), therefore allowing to better distinguish the dynamics of SDI through time. Yet, common patterns can be observed for both of them. Hence, we note a significant increase in commonalities after the explosion of the dotcom bubble (2001-2003), followed by a sharp decrease starting in 2004 and peaking in 2005. A second, more pronounced, rise in commonalities 
occurs around the financial crisis (2006-2008) and is followed (in the adaptive case) by a period of relative higher distinctiveness around 2009-2010. In the non-adaptive case, the crisis impact is more persistent considering the level of smoothing imposed (24 month). In 2012-2013 the market exhibits a higher average of distinctiveness that is immediately followed by a short yet intense commonality rise at the time of the Chinese financial crisis in late 2015. This table illustrates one caveat of using fixed window width, which tends to artificially overstate critical periods (dotcom bubble, financial crisis) and understate smaller transitive periods (2009-2010).

[Insert Table 6 about here]

\subsection{Regression analyses}

We then use a panel regression analysis setting to shed light on the impact of SDI on mutual funds' performance and identify its determinants. For the performance analysis, we use both a benchmark model in which the SDI enters linearly and alternative non-linear models to explore more complex relationships. In addition, two measures of performance are computed. In the spirit of Sun et al. (2012), we include our distinctiveness variable as a regressor to explain one-step ahead excess returns as measured by the traditional four-factor alpha. Alternatively, and to ensure consistency with the principle of style-based competition - the notion that funds compete mainly with funds following the same style - we depart from Sun et al. (2012) and construct an auxiliary dependent variable. This variable depicts the relative performance of the fund, that is, its performance compared with that of its direct competitors. Its computation is less straightforward than that for standard excess returns. For this purpose, we follow the testing procedure developed in Ardia and Boudt (2018) which allows for a formal assessment of whether pairs of estimated alphas are statistically different from one another and eventually for each fund to compute the fraction of peers that are outperformed. It is worth noting that this measure is an adaptation of the well-known "False Discovery rate" measure used by Barras et al. (2010) to peer's analysis. Hence, our second performance measure provides the proportion of competitors each funds outperforms. We further explore the link between the SDI and financial performance by looking at conditional effects. 
To this end, we include interaction terms and test for a threshold effect by adding a quadratic term. Eventually, in echo to the notion of migration risk, we examine how costly the transition phase towards innovative strategy could be by including the variation of the SDI into the model.

In a last step, we further extend the analysis to explore the drivers of distinctiveness among EEMFs. We do it by regressing our strategy distinctiveness measure on a set of individual characteristics as well as global factors. At the micro level, this final step documents the various contexts that lead funds to diverge from "the crowd," to quote Vozlyublennaia and Wu (2017). At a macro level, our study relates to the literature on commonality in the asset management industry (see Bussière, Hoerova and Klaus, 2015; Béreau, Casteleyn, Gnabo and Zwinkels, 2015) and shed light on the determinants of the fragmentation and integration phases in the EEMF industry. To that end, we regress our measure of distinctiveness on state-of-the-art fund-specific determinants (see Sun et al., 2012) and cluster- and system wide-level drivers. Table 7 provides the definition of our main variables. In Section 4.1, we further discuss the specification of each model

[Insert Table 7 about here]

\section{Results}

In this section, we provide a brief summary of the main characteristics of the EEMF market. In depth description of the industry is provided in appendix A. The European market displays several particular traits that makes it of interest to academic research. We recall them in the main lines (Table 8) before presenting our findings. For instance, mean size (TNA), age, and alpha 4 factors are respectively $234.41 € \mathrm{M}, 9.5$ years and $-0.81 \%$ (annually). These figures are very close to those reported by Ferreira et al. (2013) for EU countries ${ }^{10}$.

[Insert Table 8 about here]

\footnotetext{
${ }^{10}$ Ferreira et al. (2013) respective estimates are $251.86 \$ \mathrm{M}, 10.6$ years and $-.39 \%$ (quarterly).
} 
At a structural level, the EEMF market displays compared to the U.S. a unique combination of integration and fragmentation features. Hence, the European market is integrated as countries are applying laws which general orientation is set by the European parliament. Yet, interpretation and implementation of those aforementioned laws can to some degrees diverge across counties. Besides that, European economies can experience different macroeconomic developments or level of competition, offering contrasting environments to local mutual funds. Regarding fiscal aspects for instance, competitive tax laws in certain countries such as Ireland or Luxembourg foster the domiciliation of funds (PWC, 2018). At the funds level, some European features are also worth mentioning. Typically, in most European countries, more than $50 \%$ of domestic EEMFs' TNA are owned by commercial bank, compared to less than 20\% in the US (Ferreira, Matos and Pires, 2018). This phenomenon is due to differences in legislation between both markets (namely, the Glass-Steagall Act of 1999 separating banking and asset management activities until 1999 in the US). Against this background, we aim in this analysis to empirically document this particular segment of the mutual funds market and to unveil of some of its main features.

Turning to our results, at a macro level, our large-scale database enables to show that the EEMF population experienced a strong expansion phase from 1999 to 2009 and then fairly stabilized until 2017. Cross-country comparisons exhibit marked heterogeneity during some periods. On the one hand, Italian and Spanish data emphasized limited increases in the EMF population during the first decade of the sample and a significant decline during and after the European debt crisis. On the other hand, Luxembourg, France, and Germany (to some extent) displayed a strong expansion phase until 2009 and resisted well during the crisis, whereas Ireland data show growth in the country's EMF industry after 2009. During the two decades, our findings emphasize periods of concentration from 2000 to 2003 and from 2006 to 2011 and finally in 2015, marked by a lower number of styles and larger style-based groups, along with periods of fragmentation from 2003 to 2006, from 2012 to 2014 and 2016 characterized by relatively less populated clusters. Overall, our analysis suggests the existence of six key periods, which are characterized by three attributes: level of concentration versus fragmentation, persistence in cluster composition, and level of distinctiveness (see Table 9).

[Insert Table 9 about here] 


\subsection{Performance analysis}

Table 10 displays the estimates of the baseline equation that models the one-step ahead performance as a function of its SDI and a set of control variables. If the SDI mirrors innovative and skillful managerial talents, we should expect its estimated coefficient to be significant and positive. As described in Section 3, the set of regressors can be organized into two categories: fund-specific and cluster-specific attributes. Column I on the left reports the main results. The parameters' estimates are obtained by applying the modified version of the Sun et al. (2012) procedure ${ }^{11}$. From columns $\mathrm{I}$ to $\mathrm{V}$, the results are retrieved using an adaptive setting, namely AFFECT, using within-month daily returns (with a minimum of 18 observations). In column I, we apply GLM to estimate the coefficients. In column II we apply traditional OLS as an alternative. In column III, the autoregressive term is dropped from the specification. In the literature (see Sun et al., 2012, Ferreira et al., 2013) the dynamic nature of the process is traditionally ignored despite its strong significance as shown in the results of column I. Columns IV and $\mathrm{V}$ report the results using the more traditional absolute measure of performance with the four-factor alpha ${ }^{12}$ (Carhart, 1997).

In the second part of the table (column VI \& VII) we report the results for the non-adaptive setting. The difference with the first set of results (columns I to $\mathrm{V}$ ) lies in the setting used to recover the clusters, and in turn the performance measures and the SDI. In column VII, we strictly follow the approach of Sun et al. (2012). In column VI, we depart from the original approach by substituting the four factor alpha by the outperformance ratio. These additional models enable to compare the influence of the adaptive versus non-adaptive approach for our data.

\footnotetext{
${ }^{11}$ Specifically, our econometric approach departs from Sun et al. (2012) in four ways. First, the dependent variable is measured by the level of outperformance as provided by the testing procedure of Ardia and Boudt (2018). Second, the SDI is computed using stylebased clusters in an adaptive setting. For these clusters, we apply the AFFECT algorithm. Third, to take care of the support space of the dependent variable that displays the percentage of funds outperformed within the same cluster, we apply GLM estimators. The GLM methodology is more efficient than traditional OLS in explaining bounded variables between 0 and 1 (see Papke and Wooldridge, 1996). Fourth, we include an autoregressive term to account for potential inertia.

12 The global factors are retrieved from the French database: http ://mbtuck.dartmouth.edu/pages/faculty/ken.french/data_library.html
} 
Throughout the results, we report both the value of the coefficients and the robust t-statistics, corrected for fund-level clustering, in parenthesis. ${ }^{13}$ In the lower part of the table, we include the number of observations, the number of funds, the average observation per fund, the pseudo $R^{2}$, and the F-statistics to test whether all regressors are jointly equal to zero. The pseudo $R^{2}$ is computed by following Verbeek (2008) as the correlation of the actual and predicted values of the dependent variable.

\section{[Insert Table 10 about here]}

We start the analysis with the main model. An observation of the individual variables indicates several interesting features. The coefficient attached to SDI displays very strong statistical significance because the p-value is inferior to the $1 \%$ level when we control for time fixed effect and adjust the t-statistics for fund level clustered errors, along with a large number of fund and cluster-specific attributes. The sign of the coefficient is positive, indicating that EEMFs following a distinct strategy on average outperform close peers. Hence, a more singular strategy within styles tend to reflect management skills for EEMFs ${ }^{14}$. Economically, the outperformance ratio is expected to increase by 14.31 basis points after a one standard deviation increase in SDI. Among fund-specific attributes, all but fund flows are found to be statistically significant at the $1 \%$ level. The signs of the coefficients are in line with previous studies that explain financial excess returns. For instance, the marginal effect of fund size is negative. As discussed in Ferreira et al. (2013), the sign can be explained by the scarcity of the best investing opportunities. As the fund grows, marginal investments must be made in less performing assets, eroding the portfolio's overall performance (see Sun et al., 2012 for hedge funds, Berk and Green, 2004, Chen, Hong, Huang and Kubik, 2004, Vozlyublennaia and $\mathrm{Wu}, 2017$ for mutual funds). Another explanation is the existence of the organizational diseconomy of scale attributable, for instance, to the difficulty in processing soft information or so-called hierarchy costs (see Stein, 2002). Likewise, the sign of the variable Age is negative.

\footnotetext{
13 Such correction has become standard in this literature (see Sun et al. (2012), Ferreira et al. (2013), Vozlyublennaia and Wu (2017)).

${ }^{14}$ To the best of our knowledge, we are the first study to provide empirical evidence on strategy distinctiveness for European mutual funds.
} 
EEMFs perform less as they age. Said differently, younger funds tend to outperform their older peers. This outcome can be explained by the necessity for a fund that has been newly created, for instance, to display particularly strong performance to challenge existing institutions and to attract sufficient capital for its expansion. This result is consistent with the findings of Ferreira et al. (2013) for funds outside the United States as well as Otten and Bams (2002) regarding EEMFs. The volatility variable exhibits a positive sign such as more volatile funds tend to outperform their peers (the variable is not significant in Sun et al., 2012). Eventually, the autoregressive term is found to be statistically significant and positive, exhibiting sign of strong persistence in outperformance, consistent with the idea of skilled manager being able to outperform persistently.

Turning to cluster-specific characteristics, we first notice their high significance. This set of controls intends to account for cluster-level heterogeneity in fund performance. For instance, applying the Ardia and Boudt (2018) procedure, we might fail to detect any statistical difference in excess returns among all funds constituting a cluster. In this extreme case, the ratio of outperformance would be zero for all funds constituting the cluster. Alternatively, a cluster can exhibit marked differences across funds and be associated with a positive average ratio. Pooled altogether, the data will display clusterlevel heterogeneity that is potentially unexplained by fund-specific attributes and that we aim to capture by including this additional category of variables. All four variables are significant at the $1 \%$ or $5 \%$ levels. Cluster size displays a positive signs, indicating that funds tend to outperform more peers in large style-based clusters. Conversely, clusters including large funds as measured by the average of AUM per fund and good performing funds (estimated by their average net return) tend to lower the value of outperformance. The same holds true for clusters that are distinct from the overall market. The more innovative the style, the more difficult it is for the funds following this style to outperform their cluster peers.

We now consider the remaining columns of Table 10 (columns II to VII). For the adaptive approach (columns II to V), we notice a very strong and robust effect of SDI on financial performance, measured by either cluster-based outperformance or the more traditional four-factor alpha. We find a very strong consistency between the results of our main model in column I and alternative models using the adaptive setting (columns II to V). Neither the application of the OLS method (II) instead of GLM nor the exclusion of an autoregressive term (III \& V) affects the significance of the coefficients both for the 
outperformance ratio and four-factor alpha. We now compare the results of the adaptive approach (columns I to V) and of the non-adaptive approach (columns VI and VII). The latter corresponds to the procedure proposed by Sun et al. (2012). The strategy distinctness index is positive and significant in both approaches. Nevertheless, the comparison also displays three notable differences. First, the statistical significance is stronger for the SDI with the adaptive approach. Second, looking at the other variables, there are cases in which the conclusion regarding the statistical significance of coefficients is altered. Hence, over 10 regressors tested, we reach a different conclusion for 3 of them (column I wrt column VI). Eventually, we also notice differences with respect to the sign of the coefficient as 3 parameters display opposite signs (column I wrt column VI).

In Table 11, we explore nonlinear effects in the relationship between the SDI and funds outperformance. To this end, we extend our main model (column I) and add a new regressor constructed as the interaction among our variable of interest, SDI, and another variable driving the nonlinearity. Each interaction regressor is included in a separate regression. Overall, four types of effects are assessed. First, we test whether more innovative strategies are rewarded differently in crisis periods. For this, we consider three indicators of crisis: (i) a dummy variable for the European crisis $(E C D)$ that takes the value of 1 from January 2008 to March 2009 and from July 2011 to March $2013^{15}$ and 0 otherwise (column II), (ii) a dummy variable for the global financial crisis $(G C D)$ that takes the value of 1 from December 2007 to May 2009 and 0 otherwise (column III), and (iii) the Vstocxx that captures market uncertainty in Europe (column IV). Second, we separate within-cluster and between-cluster distinctiveness strategy. Specifically, we test whether or not it pays differently when innovative strategies are implemented within clusters that are distant from the rest of the industry (column V). Third, we investigate the existence of a change in the relationship of interest as funds become more distinct. For this, we include the SDI variable with a quadratic term (column VI). A positive coefficient for the SDI variable and a negative sign for the coefficient attached to the quadratic term suggests that beneficial effects of distinct strategy dampens as such differentiation increases. In other words, being distinct improves financial performance but the marginal effect vanishes as fund's strategy depart from its peers. Fourth, we include the

\footnotetext{
15 https://cepr.org/content/euro-area-business-cycle-dating-committee
} 
variation of the SDI (column VII) in an attempt to assess the potential cost of the transition towards more distinctive strategies which are less known by the market and for which funds managers have less expertise. This effect is captured by including the first difference of the SDI at the previous period, $\Delta S D I_{t-1}$.

\section{[Insert Table 11 about here]}

The results display significance for two models that test the effect of the crisis. Each time, the coefficients of SDI and the interaction term are positive, indicating that the effect of SDI is exacerbated in periods of stress. Hence, relative to normal times, being able to implement an innovative strategy in difficult times enables earning higher excess returns on average than close competitors. The coefficient attached to cluster Cluster-SDI*SDI is negative and statistically significant, which suggests that the more distinctive a style, the more difficult to take advantage of within-style distinctive strategy. Moving to the next column, the coefficient attached to the quadratic form of SDI displays negative statistical significance. Therefore, although the effect in our sample is strongly positive, evidence of nonlinearity exists and the marginal effect dies out as SDI grows. Eventually, our results are strongly significant for the parameter attached to $\Delta S D I_{t-1}$. It shows that a rapid shift towards more innovative strategies is associated with lower financial performances consistently with the principle of migration risk.

\subsection{Determinants of the Strategy Distinctiveness Index}

Column I in Table 12 displays the results for the reference model where coefficients are estimated by GLM. The specification includes an autoregressive term and the SDI is recovered by using the AFFECT algorithm. Columns II to III are added to test the robustness of our conclusions. Column II, the specification, is the same as in column I, but we drop the autoregressive term. Finally, in columns III SDI is computed using a rolling windows approach as in Sun et al. (2012).

[Insert Table 12 about here] 
All fund-level variables, with the exception of net flow, significantly influence the SDI. This result holds in all cases but one at the $1 \%$ significance level and is consistent across the three models. The sign of the coefficient is negative for the variable depicting the size of the fund and its age. These results are consistent with the findings of Sun et al. (2012) on US hedge funds. The interpretation for fund age and size is not straightforward. As it stands, the negative sign of the coefficient indicates that large and old funds are less prone to follow a distinctive strategy. Several mechanisms could be at play to explain this result. For instance, a fund that has developed its own investment strategy identity and is recognized in the market might have greater difficulty innovating. Likewise, when an investment has been made in specific investment skills, the cost of shifting to an alternative strategy might be high. Inversely, newly established funds have greater latitude to pursue original and innovative ideas. Small-scale funds also face less constraints from long-term clients regarding modifying their investment practices. However, we note that these conjectures about the channels through which size and age affect the SDI cannot be formally tested within our current framework. Similar to Sun et al. (2012), greater volatility is also found to be less prone to innovation. Turning to the cluster-level variables, cluster meancap and cluster SDI are shown to be positive contributors while small-cluster seems to be populated by more distinct funds.

\section{Conclusion}

In this analysis, we document the main characteristics of the EEMF industry during the past two decades. To this end, we create a novel database from Morningstar comprising 4,957 EEMFs. Equipped with these data, we use a regression approach to test whether distinct strategies - as measured by the distance of a fund's returns with the average return of their stylebased cluster - are significantly associated with excess performance. Next, we explore the determinants of strategy distinctiveness. We contribute to the literature in mainly three ways. First, we take particular care in handling several econometric issues that have been overlooked in previous contributions on strategy distinctiveness and fund's performance. To this end, we apply a modified version of the Sun et al. (2012) SDI based on the adap- 
tive clustering approach called AFFECT, which was developed by Xu et al. (2014). This method relies on a limited set of assumptions and allows us to retrieve mutual funds styles endogenously across time, dealing with changes in the number of styles, funds' shifts in style or entry and exit of funds. In addition, we apply the recent approach of Ardia and Boudt (2018) to formally test the difference in performance across peers. Second, to our knowledge, we are the first to assess the impact of strategy distinctiveness in the context of European EMFs. Third, we explore non-linear relationship between financial performance and strategy distinctiveness.

Our results show that distinctiveness among EEMFs decreased sharply prior to the crisis before increasing and eventually hitting a new low during recent months. We find a strong, robust, and positive impact of strategy distinctiveness on financial performance. Interestingly, our analysis also unveils the existence of non-linear effects. In particular, we find a decreasing marginal effect as funds become more distinct. Hence, although following innovative and distinct strategies pays off on average, the effect is actually nonlinear and exhibits a threshold level over which being too different becomes useless. Eventually, a fund's size and age are documented as significantly negative determinants of innovative strategy.

\section{References}

Ardia, D. and Boudt, K. (2018), 'The peer performance ratios of hedge funds', Journal of Banking $\&$ Finance 87, 351-368.

Banegas, A., Gillen, B., Timmermann, A. and Wermers, R. (2013), 'The cross section of conditional mutual fund performance in european stock markets', Journal of Financial economics 108(3), 699-726.

Banerjee, A., Dhillon, I., Ghosh, J., Merugu, S. and Modha, D. S. (2007), 'A generalized maximum entropy approach to bregman co-clustering and matrix approximation', Journal of Machine Learning Research 8(Aug), 19191986.

Barras, L., Scaillet, O. and Wermers, R. (2010), 'False discoveries in mutual fund performance: Measuring luck in estimated alphas', The journal of finance 65(1), 179-216. 
Béreau, S., Casteleyn, A., Gnabo, J.-Y. and Zwinkels, R. (2015), Commonality among equity mutual funds: impact on financial stability and price discovery, in 'Working Paper UNamur'.

Berk, J. B. and Green, R. C. (2004), 'Mutual fund flows and performance in rational markets', Journal of political economy 112(6), 1269-1295.

Brown, S. J. and Goetzmann, W. N. (1997), 'Mutual fund styles', Journal of financial Economics 43(3), 373-399.

Brown, S. J. and Goetzmann, W. N. (2001), Hedge funds with style, Technical report, National Bureau of Economic Research.

Bussière, M., Hoerova, M. and Klaus, B. (2015), 'Commonality in hedge fund returns: Driving factors and implications', Journal of Banking \& Finance 54, 266-280.

Carhart, M. M. (1997), 'On persistence in mutual fund performance', The Journal of finance 52(1), 57-82.

Chen, J., Hong, H., Huang, M. and Kubik, J. D. (2004), 'Does fund size erode mutual fund performance? the role of liquidity and organization', American Economic Review 94(5), 1276-1302.

Choi, J. and Kronlund, M. (2017), 'Reaching for yield in corporate bond mutual funds', The Review of Financial Studies 31(5), 1930-1965.

Clark, T. E. and McCracken, M. W. (2009), 'Improving forecast accuracy by combining recursive and rolling forecasts', International Economic Review $\mathbf{5 0}(2), 363-395$.

Cohen, R. B., Coval, J. D. and Pástor, L. (2005), 'Judging fund managers by the company they keep', The Journal of Finance 60(3), 1057-1096.

Cremers, K. M. and Petajisto, A. (2009), 'How active is your fund manager? a new measure that predicts performance', The Review of Financial Studies 22(9), 3329-3365.

Daniel, K., Grinblatt, M., Titman, S. and Wermers, R. (1997), 'Measuring mutual fund performance with characteristic-based benchmarks', The Journal of finance 52(3), 1035-1058. 
DiBartolomeo, D. and Witkowski, E. (1997), 'Mutual fund misclassification: Evidence based on style analysis', Financial Analysts Journal 53(5), 3243.

EFAMA (2017), 'Asset management in europe: An overview of the asset management industry with a special section on the capital markets union'. URL: https://www.efama.org

Ferreira, M. A., Keswani, A., Miguel, A. F. and Ramos, S. B. (2013), 'The determinants of mutual fund performance: A cross-country study', Review of Finance 17(2), 483-525.

Ferreira, M. A., Matos, P. and Pires, P. (2018), 'Asset management within commercial banking groups: International evidence', The Journal of Finance 73(5), 2181-2227.

Graef, F., Vogt, P., Vonhoff, V. and Weigert, F. (2018), 'Cash holdings and the performance of european mutual funds'.

Gupta-Mukherjee, S. (2013), 'When active fund managers deviate from their peers: Implications for fund performance', Journal of Banking \& Finance 37(4), 1286-1305.

Hartigan, J. A. (1975), Clustering algorithms, Vol. 209, Wiley New York.

Hoberg, G., Kumar, N. and Prabhala, N. (2017), 'Mutual fund competition, managerial skill, and alpha persistence', The Review of Financial Studies 31(5), 1896-1929.

Hunter, D., Kandel, E., Kandel, S. and Wermers, R. (2014), 'Mutual fund performance evaluation with active peer benchmarks', Journal of Financial economics 112(1), 1-29.

ICI (2017), 'Investment company institute - release: Worldwide regulated open-end fund assets and flows, first quarter 2017'.

URL: https://www.ici.org/pdf/2017 ${ }_{f}$ actbook.pdf

Kashima, H., Hu, J., Ray, B. and Singh, M. (2008), K-means clustering of proportional data using 11 distance, in 'Pattern Recognition, 2008. ICPR 2008. 19th International Conference on', IEEE, pp. 1-4. 
Lang, G. and Köhler, M. (2011), How does the domiciliation decision affect mutual fund fees?, Technical report, ZEW Discussion Papers.

Mao, J. and Jain, A. K. (1996), 'A self-organizing network for hyperellipsoidal clustering (hec)', Ieee transactions on neural networks 7(1), 16-29.

Matias, C. and Miele, V. (2017), 'Statistical clustering of temporal networks through a dynamic stochastic block model', Journal of the Royal Statistical Society: Series B (Statistical Methodology) 79(4), 1119-1141.

Morningstar (2016), 'Global investors shun equity, return to fixed income in 20162016 global asset flows report'.

URL: https://www.vfb.be/vfb/Media/Default/news/Morningstar.pdf

Otten, R. and Bams, D. (2002), 'European mutual fund performance', European Financial Management 8(1), 75-101.

Papke, L. E. and Wooldridge, J. M. (1996), 'Econometric methods for fractional response variables with an application to 401 (k) plan participation rates', Journal of applied econometrics 11(6), 619-632.

Patel, S. and Sarkissian, S. (2017), 'To group or not to group? evidence from mutual fund databases', Journal of Financial and Quantitative Analysis 52(5), 1989-2021.

PWC (2018), 'Benchmark your global fund distribution 2018'.

URL: $\quad h t t p s: / / w w w . p w c . l u / e n / f u n d-d i s t r i b u t i o n / d o c s / p w c-p u b l-g f d-$ march-2018.pdf

Sensoy, B. A. (2009), 'Performance evaluation and self-designated benchmark indexes in the mutual fund industry', Journal of Financial Economics 92(1), 25-39.

Shukla, R. K. and Van Inwegen, G. B. (1995), 'Do locals perform better than foreigners?: An analysis of uk and us mutual fund managers', Journal of Economics and Business 47(3), 241-254.

Stein, J. C. (2002), 'Information production and capital allocation: Decentralized versus hierarchical firms', The journal of finance 57(5), 1891-1921. 
Sun, Z., Wang, A. and Zheng, L. (2012), 'The road less traveled: Strategy distinctiveness and hedge fund performance', Review of Financial Studies 25(1), 96-143.

Verbeek, M. (2008), A guide to modern econometrics, John Wiley \& Sons.

Vozlyublennaia, N. and Wu, Y. (2017), 'Mutual funds apart from the crowd', Paper SSRN .

Whelan, K. (2014), 'Ireland's economic crisis: The good, the bad and the ugly', Journal of Macroeconomics 39, 424-440.

Xu, K. S., Kliger, M. and Hero iii, A. O. (2014), 'Adaptive evolutionary clustering', Data Mining and Knowledge Discovery 28(2), 304-336.

Yang, Y., Harris, D. P., Luo, F., Xiong, W., Joachimiak, M., Wu, L., Dehal, P., Jacobsen, J., Yang, Z., Palumbo, A. V. et al. (2009), 'Snapshot of iron response in shewanella oneidensis by gene network reconstruction', $B M C$ genomics 10(1), 131.

Zivot, E. and Wang, J. (2006), 'Modelling financial time series with s-plus', Springer pp. 429-478. 
Tab. 1. Variables of interest (1999-2016)

\begin{tabular}{llll} 
Variables & Frequency & Units & Sources \\
\hline \multirow{2}{*}{ Return } & Monthly & $\%$ & \\
Price & Daily & Euro & Morningstar \\
TNA & Monthly & Billions Euro & Morningstar \\
Age & Monthly & Years & Morningstar \\
Flow & Monthly & Billions Euro & Morningstar \\
Assigned benchmark & Point & & Morningstar \\
Vstocxx & Monthly & & Macrobond \\
\hline
\end{tabular}

Note: Table 1 reports original data frequency, unit and sources for our main variables of interest. 


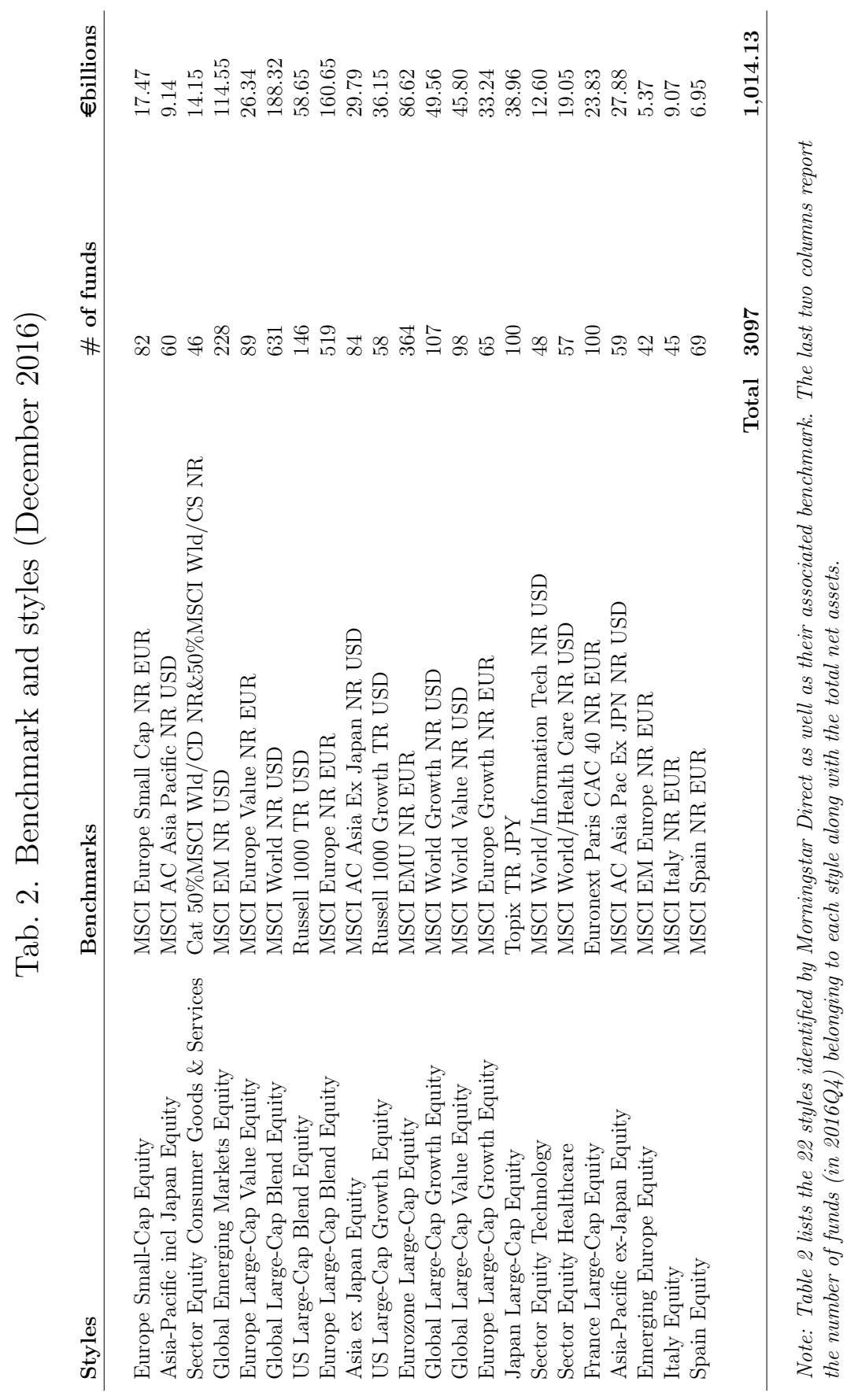


Tab. 3. EEMFs Domiciles

\begin{tabular}{|c|c|c|}
\hline Domicile & \# of funds & $\%$ of total funds \\
\hline Luxembourg & 2074 & $42 \%$ \\
\hline France & 849 & $17 \%$ \\
\hline Ireland & 424 & $9 \%$ \\
\hline Germany & 312 & $6 \%$ \\
\hline Spain & 293 & $6 \%$ \\
\hline Italy & 256 & $5 \%$ \\
\hline Belgium & 144 & $3 \%$ \\
\hline Austria & 127 & $3 \%$ \\
\hline Netherlands & 126 & $3 \%$ \\
\hline Finland & 105 & $2 \%$ \\
\hline United Kingdom & 76 & $2 \%$ \\
\hline Switzerland & 42 & $1 \%$ \\
\hline Portugal & 28 & $1 \%$ \\
\hline Slovenia & 15 & $0 \%$ \\
\hline Sweden & 14 & $0 \%$ \\
\hline Liechtenstein & 11 & $0 \%$ \\
\hline Norway & 10 & $0 \%$ \\
\hline Denmark & 10 & $0 \%$ \\
\hline Greece & 10 & $0 \%$ \\
\hline Guernsey & 8 & $0 \%$ \\
\hline Monaco & 6 & $0 \%$ \\
\hline Andorra & 5 & $0 \%$ \\
\hline Malta & 4 & $0 \%$ \\
\hline Jersey & 3 & $0 \%$ \\
\hline Isle of Man & 1 & $0 \%$ \\
\hline Gibraltar & 1 & $0 \%$ \\
\hline Estonia & 1 & $0 \%$ \\
\hline Poland & 1 & $0 \%$ \\
\hline Hungary & 1 & $0 \%$ \\
\hline
\end{tabular}

Note: Table 3 reports the number of funds per country (\# of funds) as well as their \% share with respect to the total number of funds. 
Tab. 4. Cluster statistics

\section{Cluster descriptive statistics}

Adaptive Non-adaptive

\section{Cluster Stability} Cluster Switch Average maximum cluster population Average minimum cluster population Overall maximum cluster population Overall minimum cluster population

$\begin{array}{cc}78.76 \% & 74.59 \% \\ 15.73 \% & 19.01 \% \\ 24.28 \% & 12.68 \% \\ 1.87 \% & .41 \% \\ 39.78 \% & 24.83 \% \\ .34 \% & .03 \%\end{array}$

Note: Table 4 reports cluster descriptive statistics both for the adaptive and the non-adaptive settings. In the former, clusters are determined using the AFFECT algorithm on within-month daily returns. In the later, the clusters are formed using the K-means algorithm on rolling windows of 24 months worth of returns as in Sun et al. (2012). Cluster stability measures the average \% consistency between each cluster composition in time $t$ and time $t+1$. Cluster switch refers to the probability of a fund to change style (for at least two consecutive period) over our sample. Average and overall maximum and minimum cluster population report information concerning the largest and smallest clusters. 


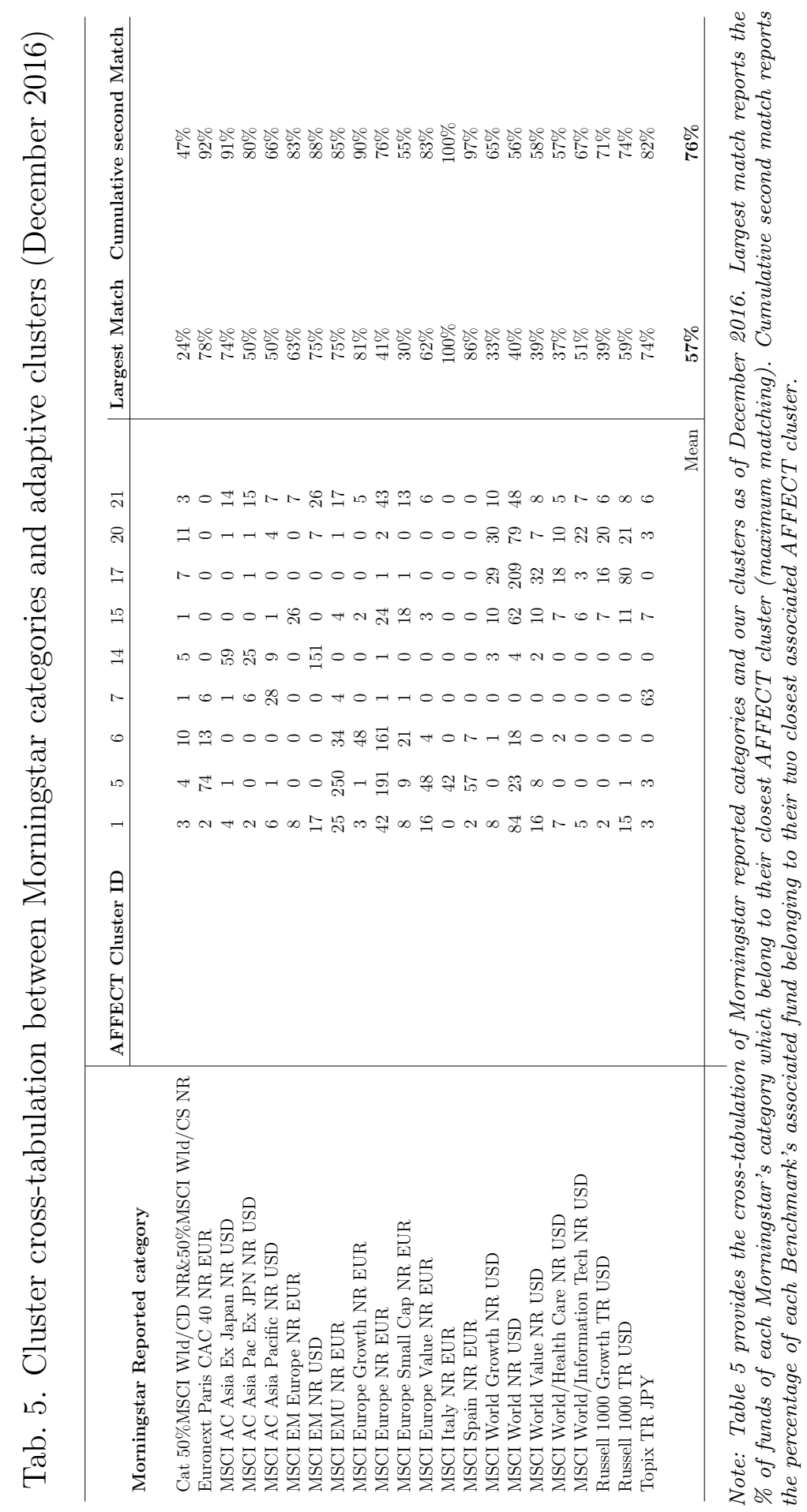


Tab. 6. SDI Dynamics

\begin{tabular}{ccc} 
Year & Adaptive & Non-Adaptive \\
\hline $\mathbf{1 9 9 9}$ & 0,1273 & NA \\
$\mathbf{2 0 0 0}$ & 0,1333 & NA \\
$\mathbf{2 0 0 1}$ & 0,1182 & 0,0721 \\
$\mathbf{2 0 0 2}$ & 0,1110 & 0,0566 \\
$\mathbf{2 0 0 3}$ & 0,1142 & 0,0429 \\
$\mathbf{2 0 0 4}$ & 0,1364 & 0,0465 \\
$\mathbf{2 0 0 5}$ & 0,1497 & 0,0658 \\
$\mathbf{2 0 0 6}$ & 0,1287 & 0,0555 \\
$\mathbf{2 0 0 7}$ & 0,1013 & 0,0588 \\
$\mathbf{2 0 0 8}$ & 0,0973 & 0,0444 \\
$\mathbf{2 0 0 9}$ & 0,1109 & 0,0420 \\
$\mathbf{2 0 1 0}$ & 0,1110 & 0,0444 \\
$\mathbf{2 0 1 1}$ & 0,1038 & 0,0558 \\
$\mathbf{2 0 1 2}$ & 0,1285 & 0,0542 \\
$\mathbf{2 0 1 3}$ & 0,1347 & 0,0615 \\
$\mathbf{2 0 1 4}$ & 0,1090 & 0,0816 \\
$\mathbf{2 0 1 5}$ & 0,0920 & 0,0606 \\
$\mathbf{2 0 1 6}$ & 0,1105 & 0,0376 \\
\hline
\end{tabular}

Note: Table 6 reports the average funds' SDI from 1999 to 2016. Column 2 reports the results in the adaptive setting while Column 3 reports those in the non-adaptive setting. 
Tab. 7. Control variables definitions

\section{Fund specific variables}

$\begin{array}{ll}\text { Fundsize } & \text { Natural logarithm of a fund's TNA in bn } \\ \text { Age } & \text { Natural logarithm of a fund's age in years } \\ \text { Flow } & \text { Change in TNA not explained by the fund's performance } \\ \text { Volatility* } & \text { Std of within-month daily net returns }\end{array}$

\section{Cluster specific variables}

Cluster-mean*

Cluster-size

Cluster-SDI*

Cluster-meancap
Average returns of the funds belonging in each cluster $\%$ of funds belonging in each cluster

SDI of cluster with respect to the overall population of funds Average size (in TNA) of funds belonging to the cluster

Note: Table 7 reports the definitions of our main fund and cluster characteristics. ${ }^{*}$ indicates that the way to compute the associated variables differ in the non-adaptive setting using 24 months of past returns instead of within-month daily returns. 
Tab. 8. European mutual funds descriptive statistics

\section{Fund descriptive statistics}

\begin{tabular}{lccc} 
& Mean & Median & Standard deviation \\
Fundsize (€bn) & 234.48 & 66.91 & 663.46 \\
Age (Years) & 9.51 & 8.17 & 7.52 \\
Flow (€bn) & -0.46 & -0.03 & 34.81 \\
Volatility & 1.08 & 0.93 & 0.65 \\
Alpha 4 Factor (Annualised \%)* & -0.81 & 0.09 & 0.22 \\
Outperformance (\%)* & 9.5 & 0 & 21.52 \\
SDI* & 0.12 & 0.08 & 0.12 \\
\hline
\end{tabular}

Note: Table 8 reports descriptive statistics concerning our main fund characteristics and performance/distinctiveness measures using the adaptive setting. ${ }^{*}$ indicates that the way to compute the associated variables differ in the non-adaptive setting using 24 months of past returns instead of within-month daily returns. 
Tab. 9. Overall Market trend

Periods Concentration levels Clusters persistence Innovation levels (Mean SDI)

\begin{tabular}{lccc}
$\mathbf{1 9 9 9}$ to 2001 & Low & Below Average & High \\
$\mathbf{2 0 0 2}$ to 2004 & Moderate & Above average & Low \\
$\mathbf{2 0 0 5}$ to 2007 & Moderate & Below Average & High \\
$\mathbf{2 0 0 8}$ to 2011 & Extreme & Average & Low \\
$\mathbf{2 0 1 2}$ to 2015 & High & Average & High \\
$\mathbf{2 0 1 5}$ to 2016 & Extreme & Below Average & Low \\
\hline
\end{tabular}

Note: Table 9 summarises the main characteristics of the European equity mutual funds across time. Based on a qualitative analysis of Figures 6 to 9, we report the overall concentration of the market (in terms of TNA, number and size of the clusters). Then using Figure 11, we report the persistence in cluster composition (\% of funds remaining in the same cluster). Finally, we display the average level of SDI as reported in Table 6 . 


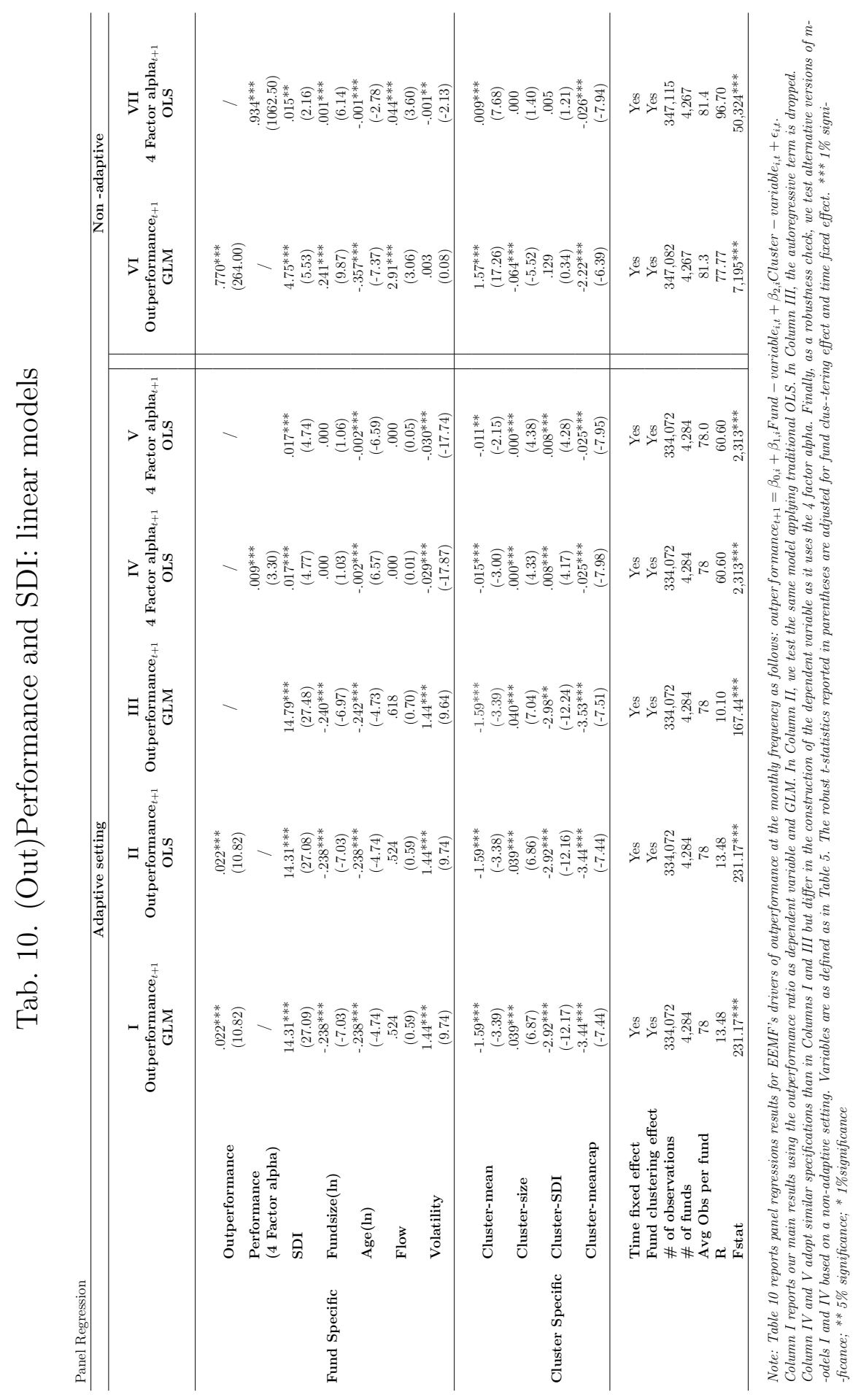


Tab. 11. Outperformance and SDI: Non-linear models

Panel Regressions

\begin{tabular}{|c|c|c|c|c|c|c|c|c|}
\hline & Outperformance $_{t+1}$ & I & II & III & IV & V & VI & VII \\
\hline & $\begin{array}{l}\text { Outperformance } \\
\text { SDI } \\
\text { SDI^2 }^{\wedge} \\
\Delta \text { SDI }_{t-1}\end{array}$ & $\begin{array}{c}.022^{* * *} \\
(10.82) \\
14.31^{* * *} \\
(27.09)\end{array}$ & $\begin{array}{c}.022^{* * *} \\
(10.83) \\
13.32^{* * *} \\
(22.89)\end{array}$ & $\begin{array}{c}.022^{* * *} \\
(10.81) \\
13.85^{* * *} \\
(25.04)\end{array}$ & $\begin{array}{l}.021^{* * *} \\
(10.45) \\
9.39^{* * *} \\
(17.44)\end{array}$ & $\begin{array}{c}.021^{* * *} \\
(10.56) \\
17.53^{* * *} \\
(22.14)\end{array}$ & $\begin{array}{c}.020^{* * *} \\
(9.96) \\
26.70^{* * *} \\
(26.07) \\
-23.00^{* * *} \\
(-12.88)\end{array}$ & $\begin{array}{c}0.21^{* * *} \\
(10.12) \\
17.95^{* * *} \\
(27.93) \\
\\
-8.28^{* * *} \\
(-15.01) \\
\end{array}$ \\
\hline Fund specific & $\begin{array}{l}\text { Fundsize(ln) } \\
\text { Age(years) } \\
\text { Flow } \\
\text { Volatility }\end{array}$ & $\begin{array}{c}-.238^{* * *} \\
(-7.03) \\
-.238^{* * *} \\
(-4.74) \\
.524 \\
(0.59) \\
1.44^{* * *} \\
(9.74)\end{array}$ & $\begin{array}{c}-.239^{* * *} \\
(-7.07) \\
-.238^{* * *} \\
(-4.75) \\
.531 \\
(0.60) \\
1.49^{* * *} \\
(10.00)\end{array}$ & $\begin{array}{c}-.238^{* * *} \\
(-7.05) \\
-.237^{* * *} \\
(-4.74) \\
.530 \\
(0.60) \\
1.50^{* * *} \\
(9.88)\end{array}$ & $\begin{array}{c}-.197^{* * *} \\
(-5.85) \\
-.266^{* * *} \\
(-5.38) \\
1.04 \\
(0.98) \\
1.30^{* * *} \\
(12.04)\end{array}$ & $\begin{array}{c}-.233^{* * *} \\
(-6.94) \\
-.236^{* * *} \\
(-4.74) \\
.495 \\
(0.56) \\
1.46^{* * *} \\
(9.84)\end{array}$ & $\begin{array}{c}-.223^{* * *} \\
(-6.94) \\
-.222^{* * *} \\
(-4.53) \\
.449 \\
(0.51) \\
1.64^{* * *} \\
(11.26)\end{array}$ & $\begin{array}{c}-.218^{* * *} \\
(-6.50) \\
-210^{* * *} \\
(-4.11) \\
.126 \\
(1.18) \\
1.475^{* * *} \\
(10.16)\end{array}$ \\
\hline Style Specific & $\begin{array}{l}\text { Cluster-mean } \\
\text { Cluster-size } \\
\text { Cluster-SDI } \\
\text { Cluster-meancap }\end{array}$ & $\begin{array}{c}-1.59^{* * *} \\
(-3.39) \\
.039^{* * *} \\
(6.87) \\
-2.92^{* * *} \\
(-12.17) \\
-3.44^{* * *} \\
(-7.44) \\
\end{array}$ & $\begin{array}{c}-1.61^{* * *} \\
(-3.44) \\
.039^{* * *} \\
(6.84) \\
-2.92^{* * *} \\
(-12.20) \\
-3.49^{* * *} \\
(-7.55) \\
\end{array}$ & $\begin{array}{c}-1.58^{* * *} \\
(-3.38) \\
.040^{* * *} \\
(7.07) \\
-2.88^{* * *} \\
(-11.98) \\
-3.36^{* * *} \\
(-7.25) \\
\end{array}$ & $\begin{array}{c}1.57^{* * *} \\
(7.45) \\
.049^{* * *} \\
(9.23) \\
-2.92^{* * *} \\
(-12.64) \\
-3.08^{* * *} \\
(-7.35) \\
\end{array}$ & $\begin{array}{c}-1.57^{* * *} \\
(-3.36) \\
.047^{* * *} \\
(8.11) \\
-1.64^{* * *} \\
(-5.33) \\
-3.58^{* * *} \\
(-7.74) \\
\end{array}$ & $\begin{array}{c}-1.69^{* * *} \\
(-3.60) \\
.052^{* * *} \\
(9.45) \\
-2.99^{* * *} \\
(-12.65) \\
-4.13^{* * *} \\
(-8.94) \\
\end{array}$ & $\begin{array}{c}-1.464^{* * *} \\
(-3.11) \\
.050^{* * *} \\
(8.83) \\
-3.051^{* * *} \\
(-12.61) \\
-.361^{* * *} \\
(-7.75) \\
\end{array}$ \\
\hline Global & Vstocxx & & & & $\begin{array}{c}-.126^{* * *} \\
(-17.87)\end{array}$ & & & \\
\hline Interaction variables & $\begin{array}{l}\text { ECD * SDI } \\
\text { GCD*SDI } \\
\text { Vstocxx*SDI } \\
\text { Cluster-SDI * SDI }\end{array}$ & & $\begin{array}{c}3.85^{* * *} \\
(4.33)\end{array}$ & $\begin{array}{c}4.07^{\text {*** }} \\
(3.27)\end{array}$ & $\begin{array}{l}.283^{* * *} \\
(14.24)\end{array}$ & $\begin{array}{c}-8.12^{* * *} \\
(-5.60)\end{array}$ & & \\
\hline & $\begin{array}{l}\text { Fund clustering effect } \\
\text { Time fixed effect } \\
\text { \# of observations } \\
\# \text { of funds } \\
\text { Avg Obs per fund } \\
\text { R } \\
\text { Fstat }\end{array}$ & $\begin{array}{c}\text { Yes } \\
\text { Yes } \\
334.072 \\
4,284 \\
78 \\
13.48 \\
231.17^{* * *}\end{array}$ & $\begin{array}{c}\text { Yes } \\
\text { Yes } \\
334.072 \\
4,284 \\
78 \\
13.51 \\
231.77^{\text {*** }}\end{array}$ & $\begin{array}{c}\text { Yes } \\
\text { Yes } \\
334.072 \\
4,284 \\
78 \\
13.50 \\
231.57^{* * *}\end{array}$ & $\begin{array}{c}\text { Yes } \\
\text { No } \\
333,968 \\
4,284 \\
78 \\
8.54 \\
2,353^{* * *}\end{array}$ & $\begin{array}{c}\text { Yes } \\
\text { Yes } \\
334.072 \\
4,284 \\
78 \\
13.54 \\
232.36^{* * *}\end{array}$ & \begin{tabular}{|c|} 
Yes \\
Yes \\
334.072 \\
4,284 \\
78 \\
13.82 \\
$237.94^{* * *}$
\end{tabular} & $\begin{array}{c}\text { Yes } \\
\text { Yes } \\
334.072 \\
4,284 \\
78 \\
13.91 \\
239.73^{* * *}\end{array}$ \\
\hline
\end{tabular}

Note: Table 11 reports panel regressions results where our baseline model is extended to account for non-linear effects. Column I and II report the interaction variables between SDI and an European crisis dummy ECD (II) or a global crisis dummy GCD (III). Column IV rep-orts the results while using a market volatility variable Vstocxx rather than time fixed effect as an interaction variable. Column $V$ uses clu-ster-SDI as an interaction variable, while column VI includes a quadratic form for the SDI. Finally, Column VII tests for style drift risk. Fund and cluster variables are identical to Table 5. The robust t-statistics reported in parentheses are adjusted for fund clustering effect an-d time fixed effect. ${ }^{* *} 1 \%$ significance; ${ }^{*} 5 \%$ significance; ${ }^{*} 10 \%$ significance. 


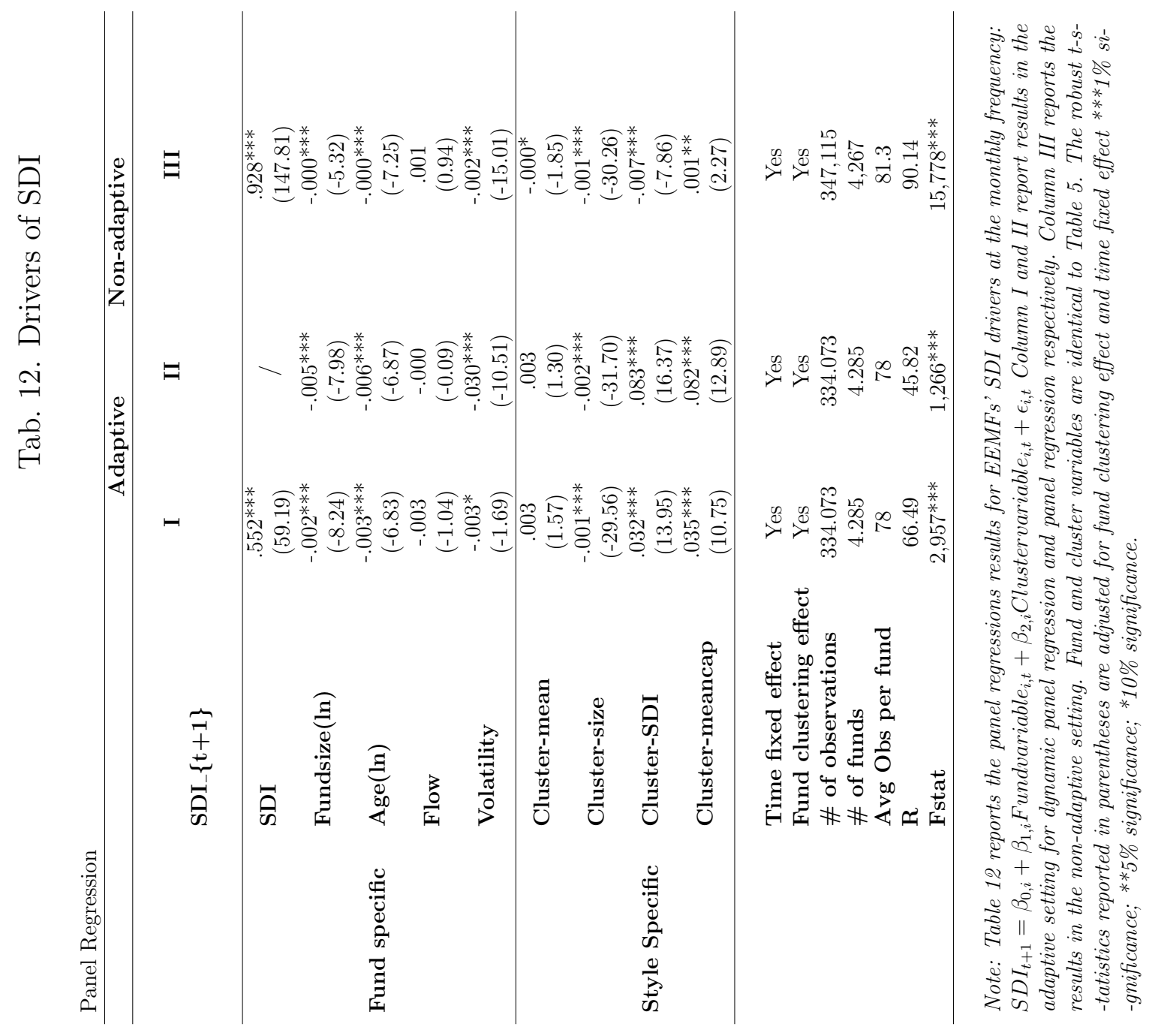




\section{Appendix A: An overview of the European eq- uity mutual funds market}

\section{A.1: Country based analysis}

Figure 1 shows the number of active mutual funds comprising our sample across time and dispatched by countries. A visual inspection shows marked differences in our sample, with Luxembourg and France capturing more than $50 \%$ of the total number of EMFs in Europe (see also Table 1). On the other side, Portugal,Sweden,and Slovenia altogether host only 2\% of European mutual funds. These numbers are in line with Graef et al. (2018) based on 1,464 funds, and we account for 4,957. EMFs domicile used in the study are based on Morningstar.

[Insert Figure 1 about here]

With this in mind, we turn to the evolution of the EEMF market and note both similarities and differences across countries. First, taken as a whole, the industry displays two separate phases. The first is an expansion phase from 1999 to the end of 2008. During this period, the total number of funds in Europe increased sharply to reach an all-time high of 3,497 from 1,310. This trend subsequently vanishes, and the industry enters a stabilizing or slightly contracting phase. In December 2016, we denote a total of 3,049 funds, down by $13 \%$ from the historical peak. A more careful inspection enables a separation of contrasting behaviors across countries. The global picture is partially driven by Luxembourg, in which the expansion phase was particularly marked. The same applies to Ireland. Both countries experienced very strong growth in the number of local funds that materialized into significant market share gains. Figure 2 displays the market share per country across time. France and Germany maintained a fairly similar market share throughout our sample. No comparable pattern is observable for Italy and Spain, which overall lost some ground relative to other nations during 1999-2016. Following 2009, the number of funds decreased in Italy and Spain, remained

fairly stable in Luxembourg, Germany, and France, and increased slightly in Ireland. 
[Insert Figure 2 about here]

Before proceeding with our analysis, it is worth noting that we cannot, using our data, formally identify the underlying factors driving the diverging trends. Nevertheless, from the literature on mutual fund developments, we can recall some established features and confront them with respect to our figures. Traditionally, the mutual fund industry is argued to respond to various factors, such as capital inflows from investors, that can be sensitive to competition from alternative investment vehicles such as ETFs or the market environment. The two factors are drivers of the liability and the asset side of mutual funds (Vozlyublennaia and Wu, 2017). More recently, changes in regulations have also been mentioned as determinants of mutual fund development amid the implementation of the MiFiD II regulation that has been blamed by the industry for dramatically raising operating costs and penalizing small-scale structures. Our data show that the dates of the successive turning points correspond fairly well to financial events consistent with some of the drivers previously mentioned, especially the burst that caused the so-called European debt crisis. We also notice that the 2007-2009 financial crisis rooted in the U.S. economy had a significant impact on the EEMF market when considering the number of active mutual funds. In 2016, we observed a slight decrease in the number of mutual funds that could correspond to the implementation of regulatory reforms within MiFiD. However, in this descriptive phase, we cannot formally isolate the effect of regulation from other factors. Regarding cross-country comparisons, one way to interpret the heterogeneity in our data is to consider the location of mutual fund investments. Our sample includes both mutual funds engaged primarily in foreign investments and funds with an informational advantage engaged in local investments. ${ }^{16}$ For instance, mutual funds in Luxembourg are known to follow a worldwide strategy (Lang and Köhler, 2011). In contrast, Italy and Spain host mutual funds investing both abroad and locally. As a result, the strong impact of the European crisis on these two countries may have spilled over to local mutual funds. Mutual funds in Luxembourg, along with France and Germany, resisted the European turbulences more forcefully because of either lower dependence on the local market or better resilience of their domestic economy to the crisis. Interestingly, Ireland whose econ-

\footnotetext{
16 As discussed in the literature, mutual funds possess local knowledge and privileged contacts with companies and market participants (see Shukla and Van Inwegen (1995))
} 
omy was dramatically hurt in 2008 and 2010 (Whelan, 2014), experienced an expansion of mutual fund activity. This finding supports the notion that mutual funds with an international investment strategy were better protected between 2008 and 2011.

Figures 3 and 4 complete the picture by considering the total amount under management as well as the average size of EMFs per country. We now analyze whether a particular segment of the market and, specifically, smallscale funds, were more affected by successive changes in the economic and regulatory environment. As expected, the evolution of total AUM is more volatile than the number of funds. Although remaining relatively low, the AUM increased dramatically in 2005 and continued to grow until the end of 2007. The occurrence of the U.S. financial crisis seems to have reverted the trend because the AUM sharply declined from approximately 800 billion in 2007 to approximately 275 billion in 2009. Next, the EEMF industry resumed its growth until 2016 with two temporary episodes of slight decreases in 2011 and 2016. Figure 4 reports the average fund size. We observe a marked difference with the previous graph. In particular, from 1999 to 2002, although the industry was small relative to the rest of the sample, the average size was quite large. Therefore, this period was marked by a concentration of the market with a limited number of players but of large size. Unsurprisingly, the crisis affected the stock market and the value of the EEMF portfolio. The average size bounced back early during the crisis and started to grow again from 2009. Regarding the total AUM, the upward trend was discontinued twice in 2011 and 2016. Overall, no evidence from these results show that the architecture of the mutual fund industry has been markedly distorted across time. There is widespread concern in the industry that increasing demand from regulators might lead to consolidation of the global fund industry to maintain profitability. In our data, we do not pick up on an eviction of small-scale funds following the implementation of new regulations.

[Insert Figure $3 \& 4$ about here] 


\section{A.2 Style-based analysis}

The previous subsection discusses country-based categories. In the following section, we explore the key features of the EEMF industry by considering style-based classifications. As presented in Section 3, our methodology enables the recovery of the number and the composition of clusters through time. Recall that mutual funds included in the same cluster exhibit close dependence in their returns. One way to interpret these clusters is to consider that they group together mutual funds that follow the same style and, as such, those set in competition. Figure 5 displays the number of style-based clusters from 1999 to 2016. On average, the industry can be divided into 13 styles. After a sharp decrease around the dotcom bubble, their number remains relatively stable across time, with a slight decrease in 2008, 2011, and 2016.Our result points to an interesting feature. While more product have been made available in the industry EFAMA (2017), we do find that it eventually goes along with more similarity in their returns. This finding would be interesting to be further investigated with the help of portfolio holding data for instance. This direction of research is however, left for future investigations.

\section{[Insert Figure 5 about here]}

Figure 6 reports the size of style-based clusters across time. The vertical axis displays the decile to which each cluster is attached. Each cluster is represented by a circle whose size and color reflect the number of mutual funds included. Large clusters appear in 2001, and their number continues to increase. The largest structures are concentrated between 2007 and 2011. For instance, we count 1,170 mutual funds in a single cluster in March 2009. After 2012, we count a maximum of 966 institutions in a cluster. However, we observe more clusters in the last decile, supporting increased industry concentration.

[Insert Figure 6 about here]

Figure 7 indicates the cluster size considering the total AUM per cluster instead of the number of institutions. Two periods emerge. First, we observe 
a strong concentration in the industry between 2007 and 2008. Next, the market becomes more fragmented before again displaying signs of increased concentration in 2011 and 2015. Larger clusters are visible in 2007-2008 and 2015-2016. Overall, we consistently document periods of strong integration that could go along with increased competition in 2001-2003, 2007-2008, and 2015-2016, characterized by a lower number of styles, more populated clusters, and larger sizes, along with phases of fragmentation in which we observe a stable number of smaller-scale clusters as measured by the number of funds and smaller funds, as in 2005-2007 and 2011-2013.

\section{[Insert Figure 7 about here]}

Next, we analyze the distinctiveness strategy of the funds. Figures 8 and 9 display (i) the size of clusters as measured alternatively by the number of funds and the AUM, along with (ii) the average SDI per cluster. Clusters with the highest average SDI are displayed in the upper part of the figure. Inversely, the most homogeneous clusters are displayed in the lower part of the figure. From the two figures, we do not observe a clear correlation between the level of distinctiveness and cluster size. For instance, in 2016, a large cluster is highly homogeneous, whereas in 2013, a fairly large cluster is heterogeneous. This bivariate analysis result tends to suggest that distinct strategies are not more likely in a more populated and competitive environment.

[Insert Figure $8 \& 9$ about here]

In the next figure, we compute the distinctiveness of the clusters themselves. To this end, we compare the average return of the entire industry and the average return over the cluster. Figure 10 shows the results. More distinct clusters are reported on the upper part of the figure. Clusters more in line with the rest of the industry are displayed in the lower part of the figure. The size of the circle depicts the average distinctiveness of the components of the cluster. Here, too, we cannot isolate specific regularities. For instance, in 2005, the two most distinct clusters are highly homogeneous and heterogeneous, respectively. 
[Insert Figure 10 about here]

A final aspect that we discuss in this section is with regard to the dynamic nature of our system and, more specifically, changes in the composition of clusters and the SDI measure. An implicit assumption in the analysis is that funds select their style in the first place. Then, they proceed to make "marginal" adjustments in the strategy to distinguish themselves from competing peers. In accordance, we should observe a high level of inertia in the composition of clusters and greater variability in the distinctiveness measure. Note, however, the two are not directly comparable. Nevertheless, we can document the persistence of the mutual fund cluster and whether such persistence has evolved over time. On average, a fund in two consecutive periods remains in the same cluster at $85 \%$. That is, $85 \%$ of the funds at time $t$ remain in the same cluster in time $t+1$. This supports the principle of inertia previously discussed. If we observe the evolution of this indicator, we see that the persistence has exhibited strong consistency overtime (Figure 11). Hence, the minimum match between two periods was achieved in the year 2000 with $65 \%$ consistency.

[Insert Figure 11 about here] 
Fig. 1. Total population of funds by country

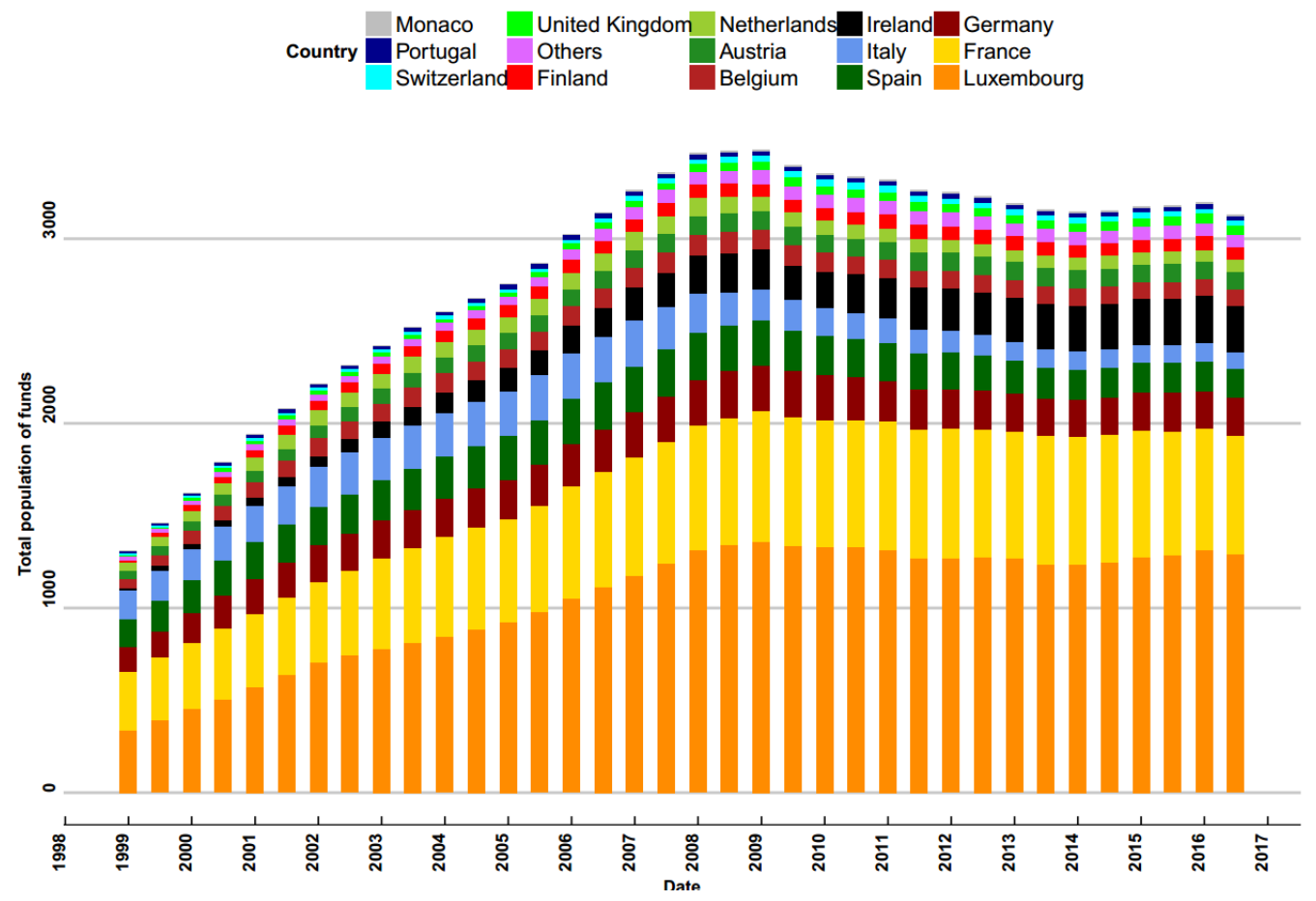

Note: Figure 1 reports the total number of funds by country from 1999 to 2016. 
Fig. 2. Relative population of funds by country

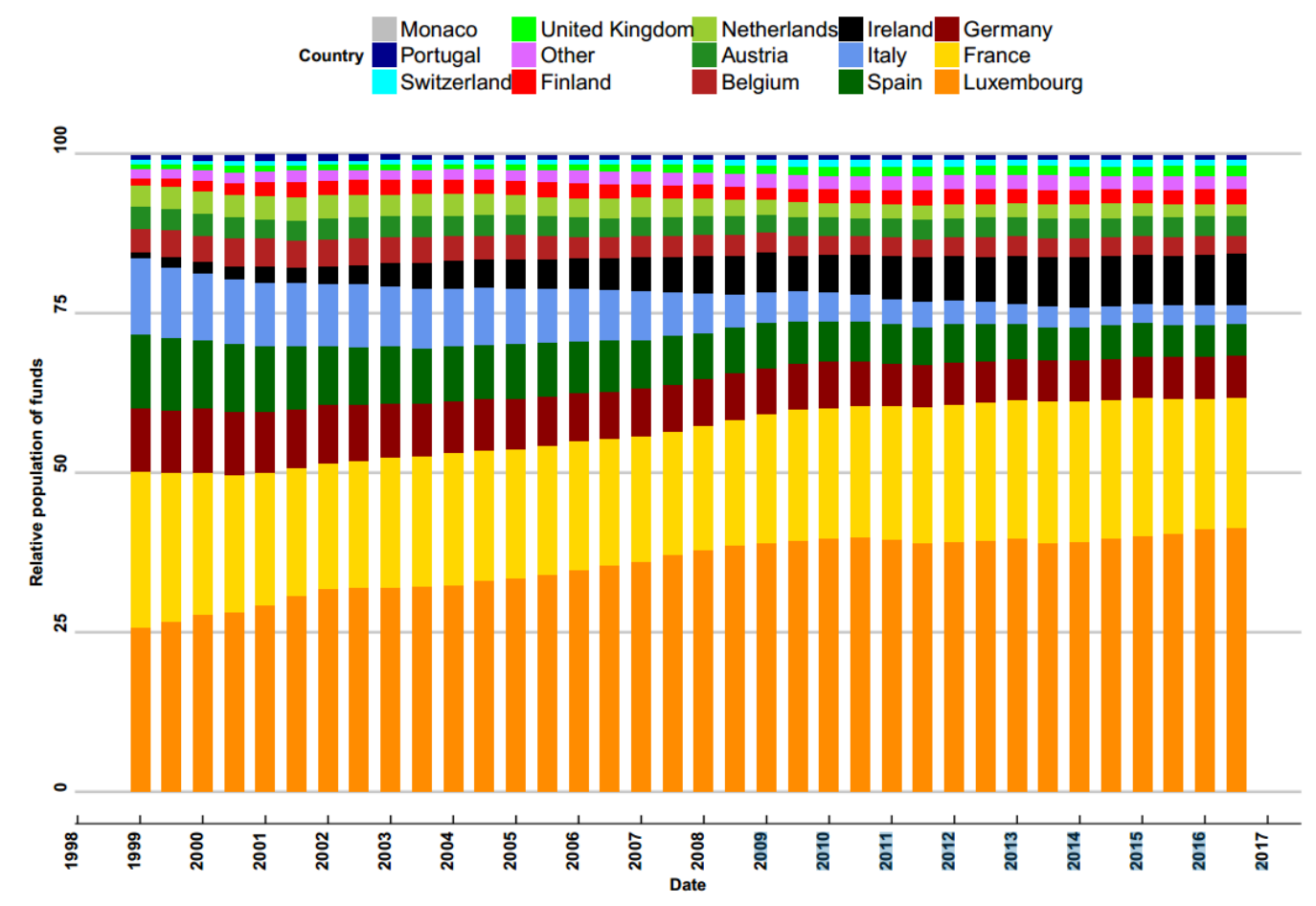

Note: Figure 2 reports the share of funds by country from 1999 to 2016. 
Fig. 3. Total TNA per country

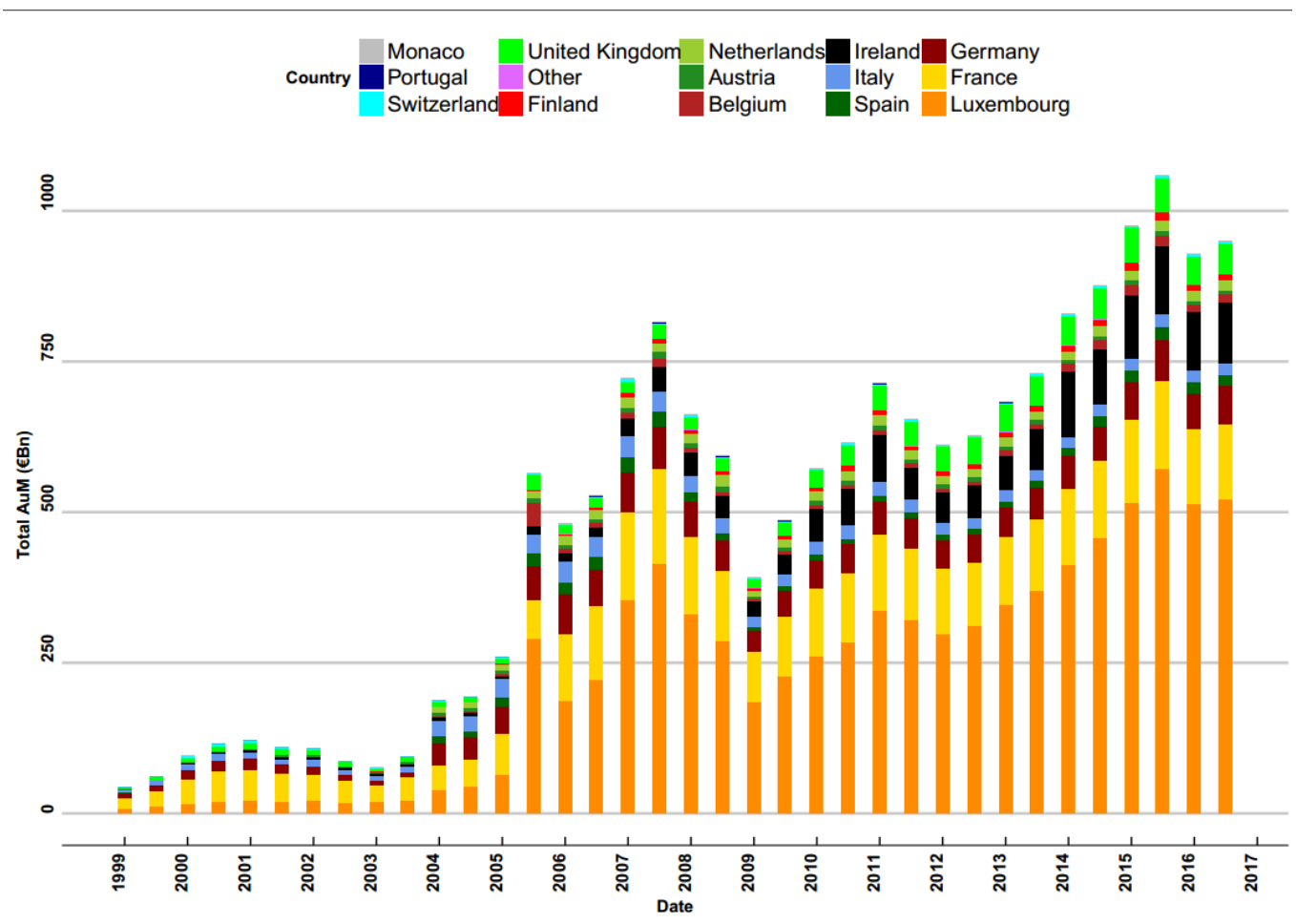

Note: Figure 3 reports the total TNA (in $€ B n$ ) of funds by country from 1999 to 2016. 
Fig. 4. Relative TNA per country's population of funds

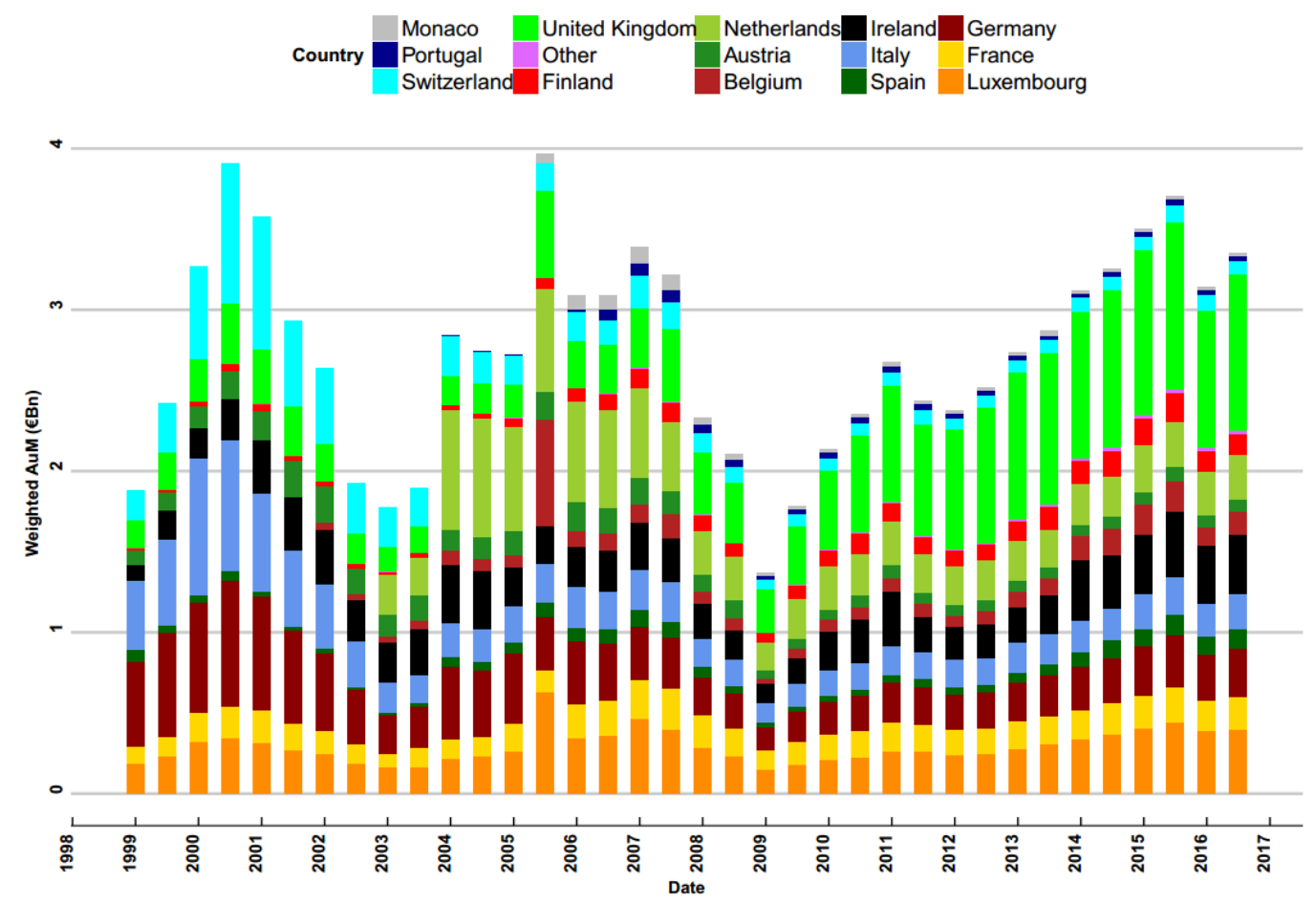

Note: Figure 4 reports the share of funds by country from 1999 to 2016, the total TNA (in $€ B n$ ) of each of our funds' domicile country weighted by the number of funds available in this particular country. 
Fig. 5. Time-varying cluster number

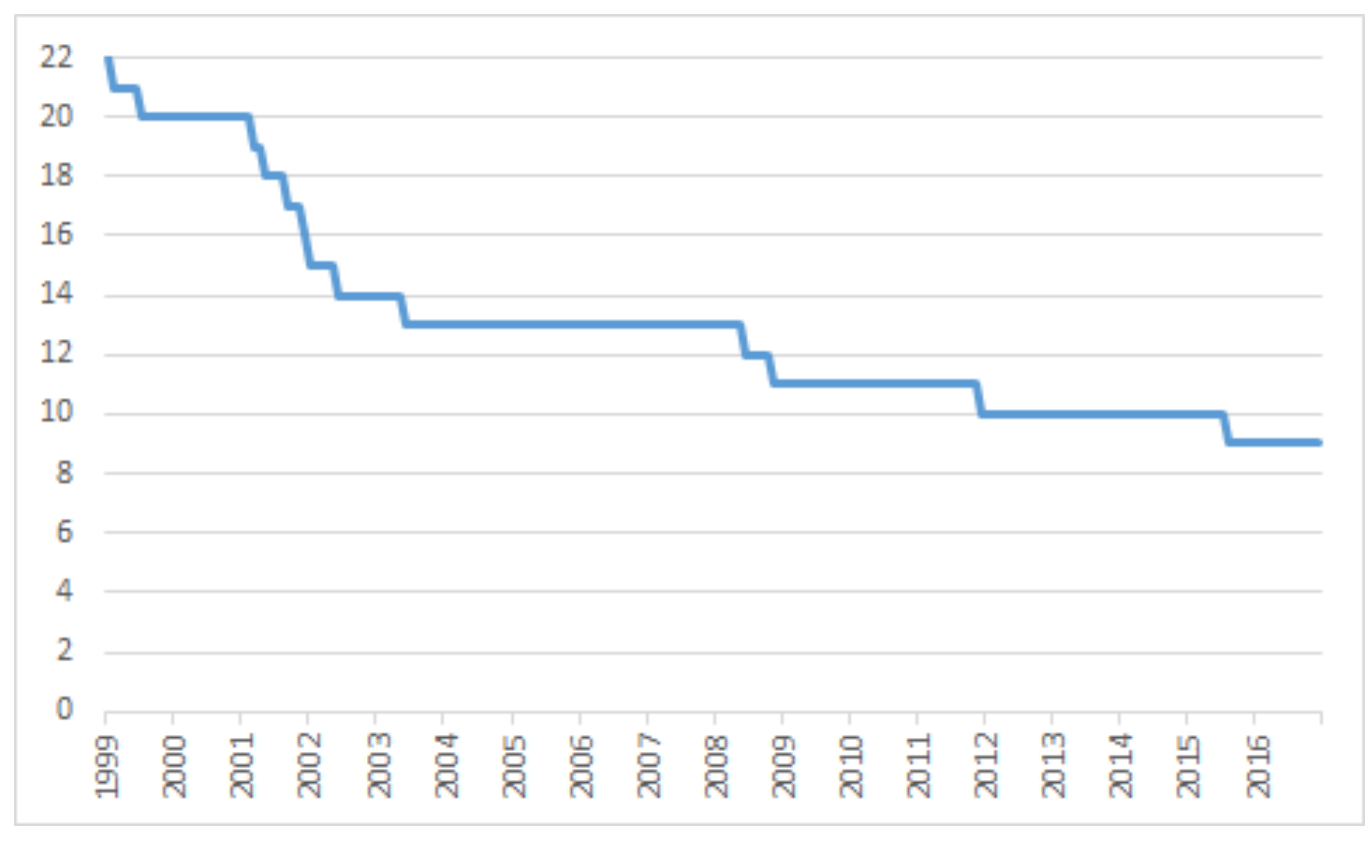

Note: Figure 5 reports the optimal number of cluster computed by the adaptive approach from 1999 to 2016. 
Fig. 6. Size of style-based cluster

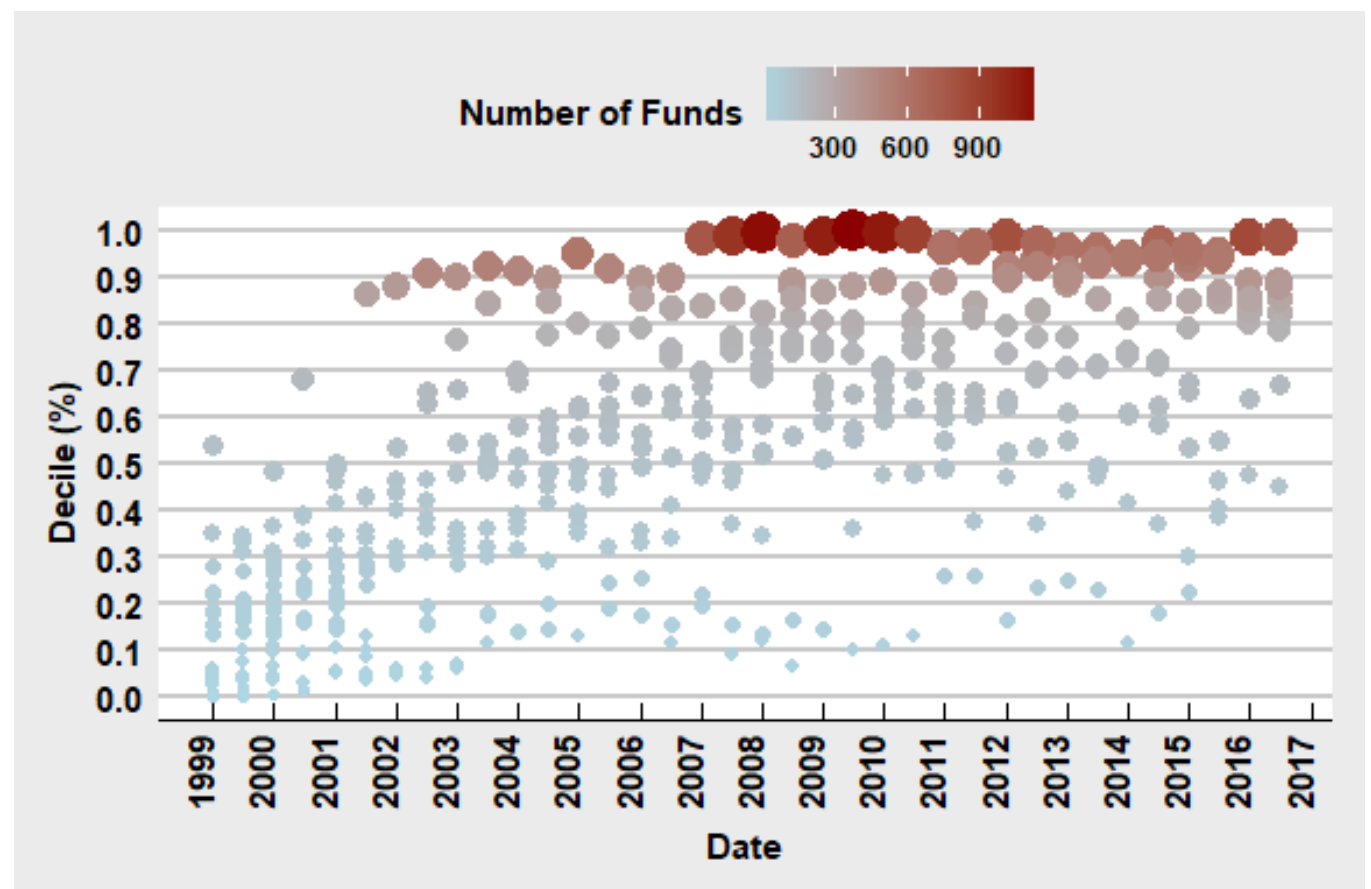

Note: Figure 6 reports the total number of funds (reported in deciles) by cluster from 1999 to 2016. 
Fig. 7. Total TNA of style-based cluster

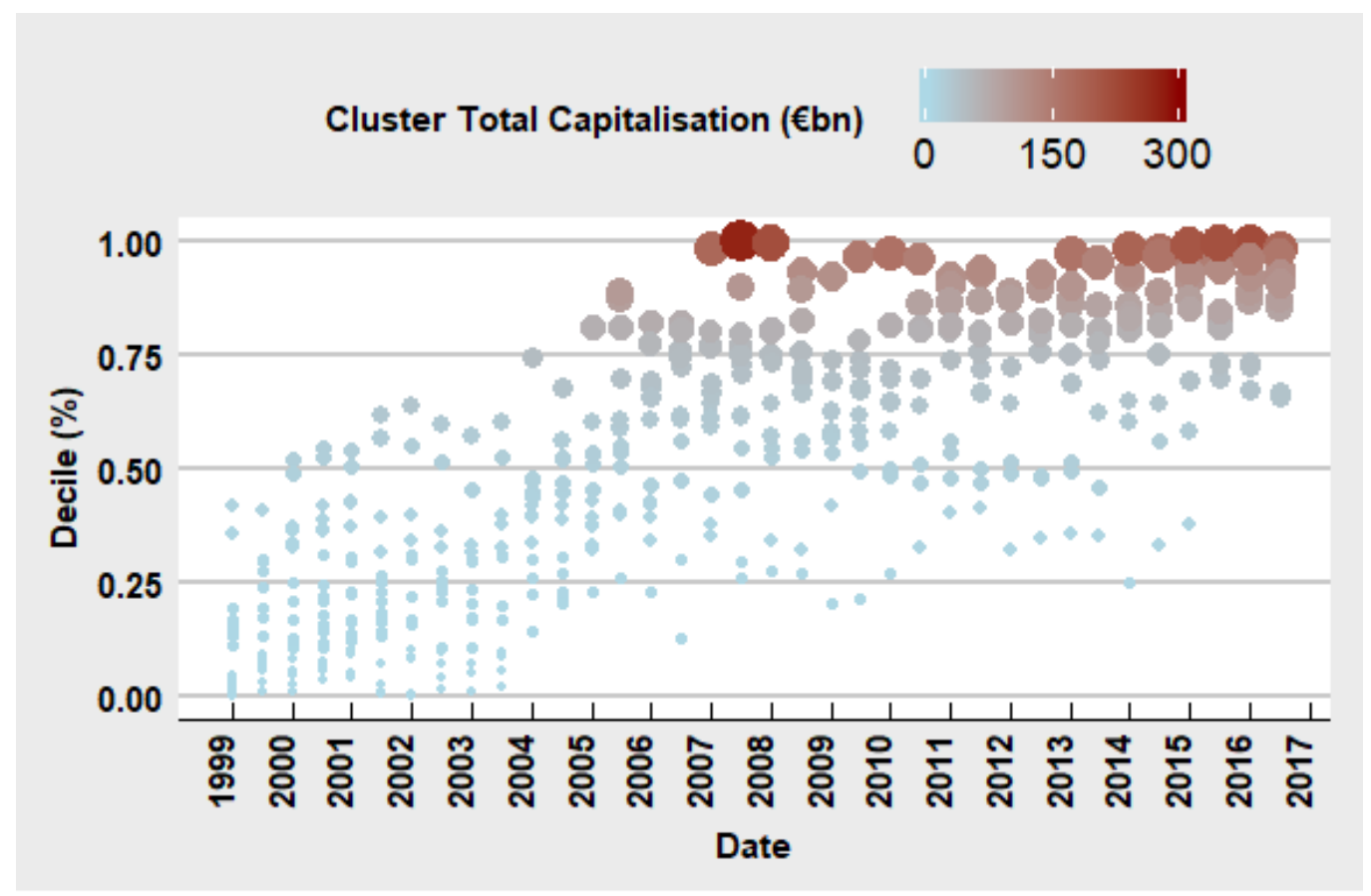

Note: Figure 7 reports the average funds' TNA (reported in deciles) by cluster from 1999 to 2016. 
Fig. 8. Cluster mean SDI vs. number of funds

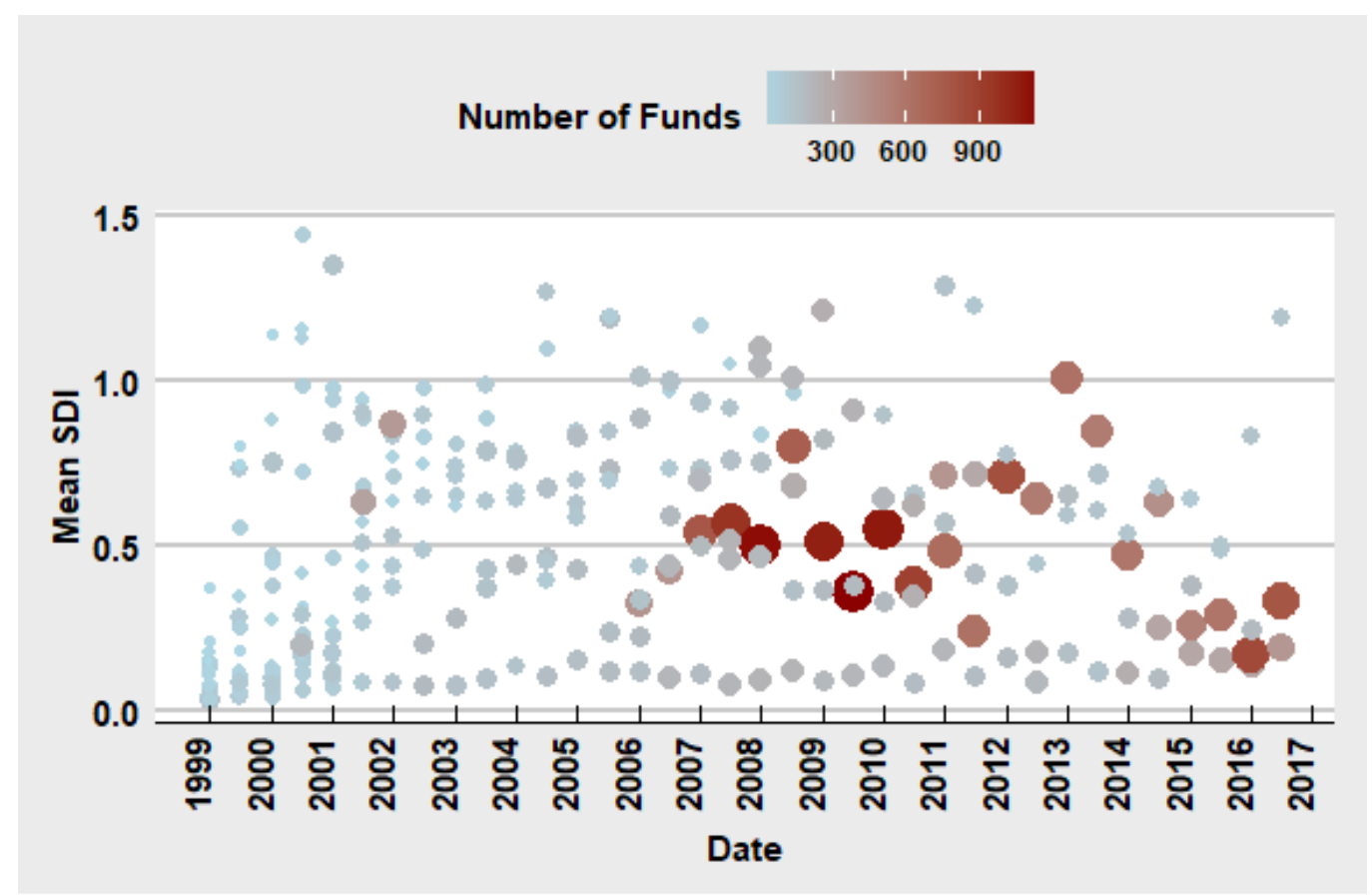

Note: Figure 8 reports the average funds' SDI (reported in deciles) and number of funds by cluster from 1999 to 2016. 
Fig. 9. Cluster mean SDI vs. total capitalization

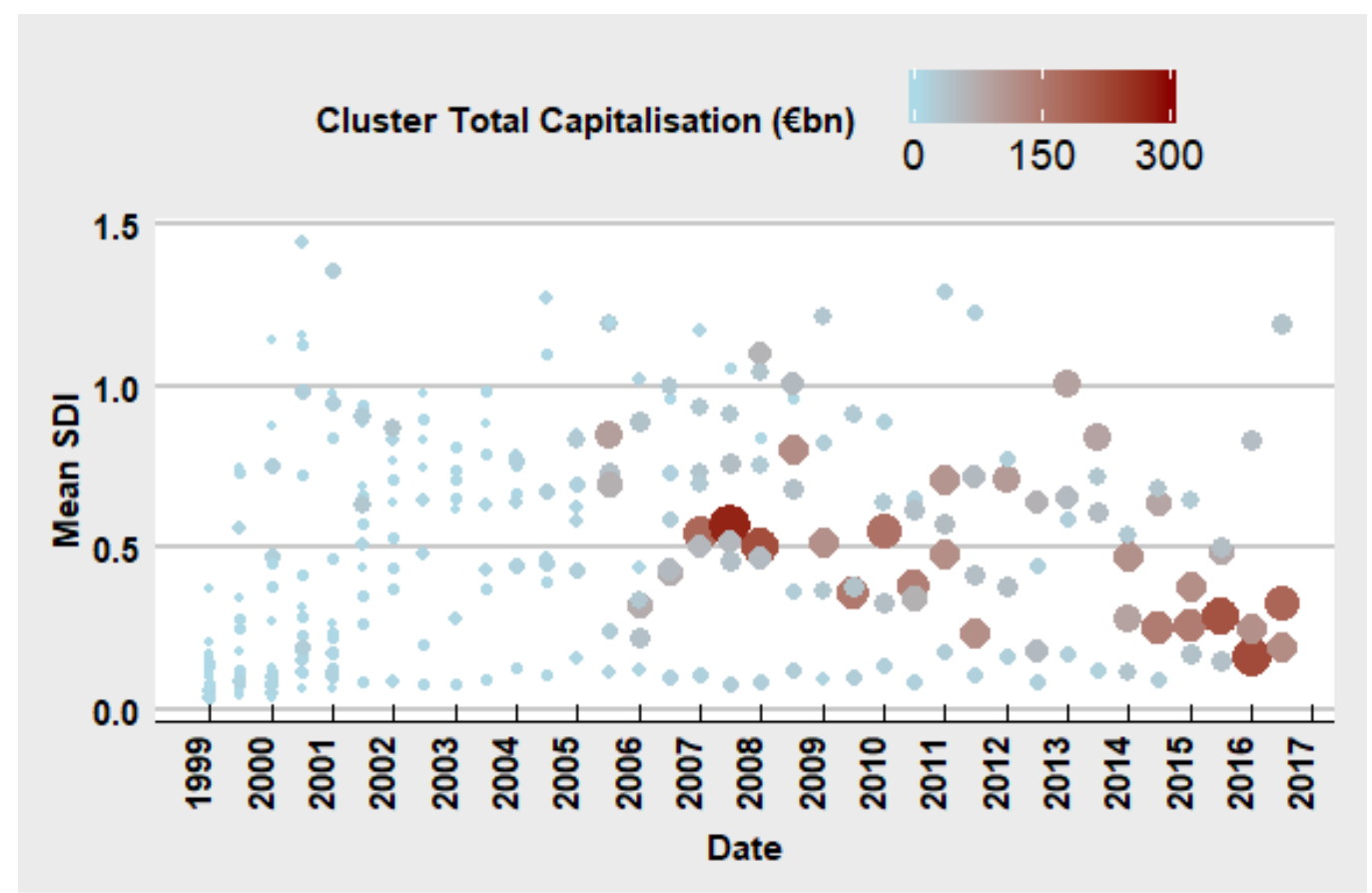

Note: Figure 9 reports, the average funds' SDI (reported in deciles) and TNA by cluster from 1999 to 2016. 
Fig. 10. Cluster mean SDI vs. Cluster SDI

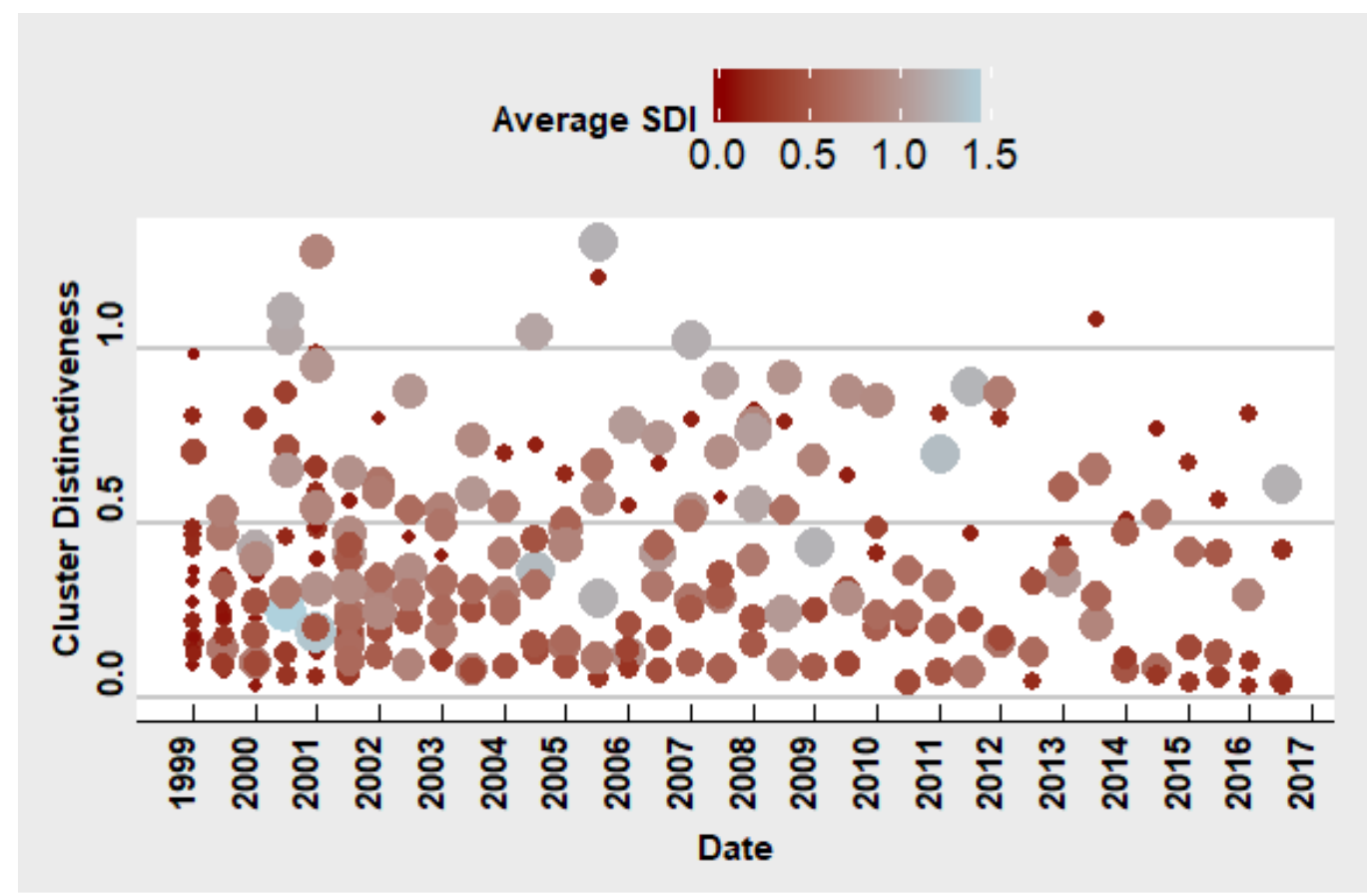

Note: Figure 10 reports the average Cluster-SDI (reported in deciles) and funds' SDI by cluster from 1999 to 2016. 
Fig. 11. Cluster stability across time

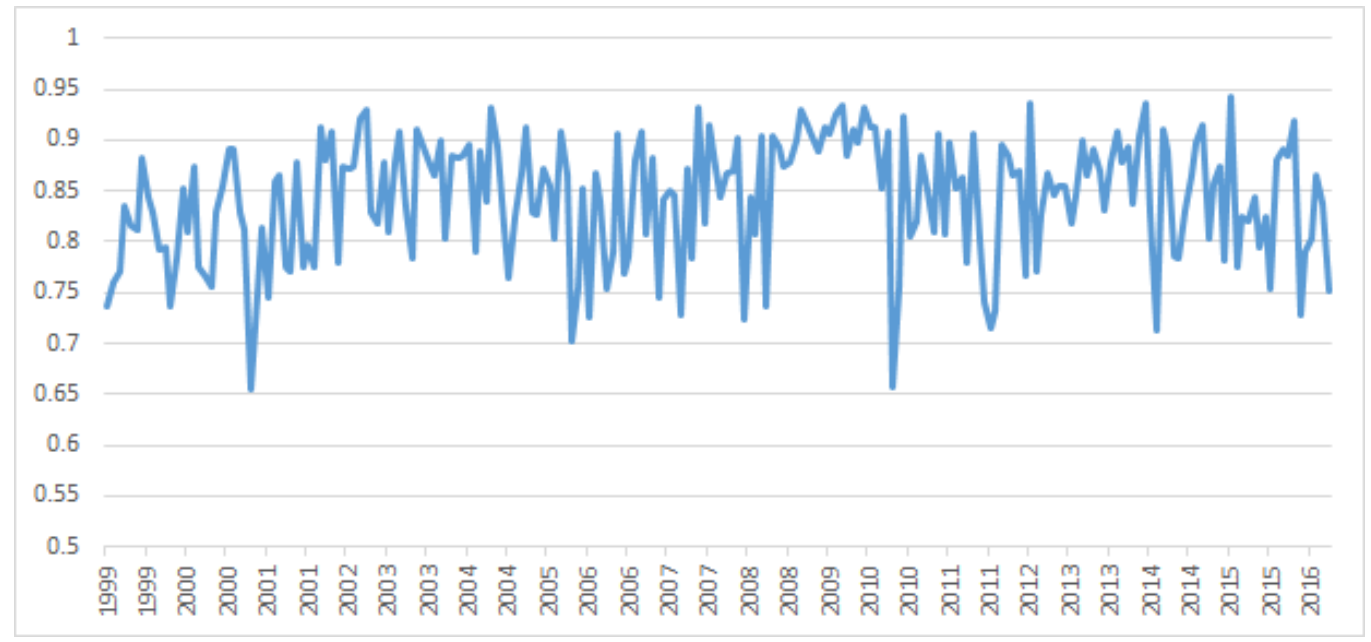

Note: Figure 11 reports the average stability in clusters' funds composition from one period to the next. 